\title{
Frontal white matter volume and delta EEG sources negatively correlate in awake subjects with mild cognitive impairment and Alzheimer's disease
}

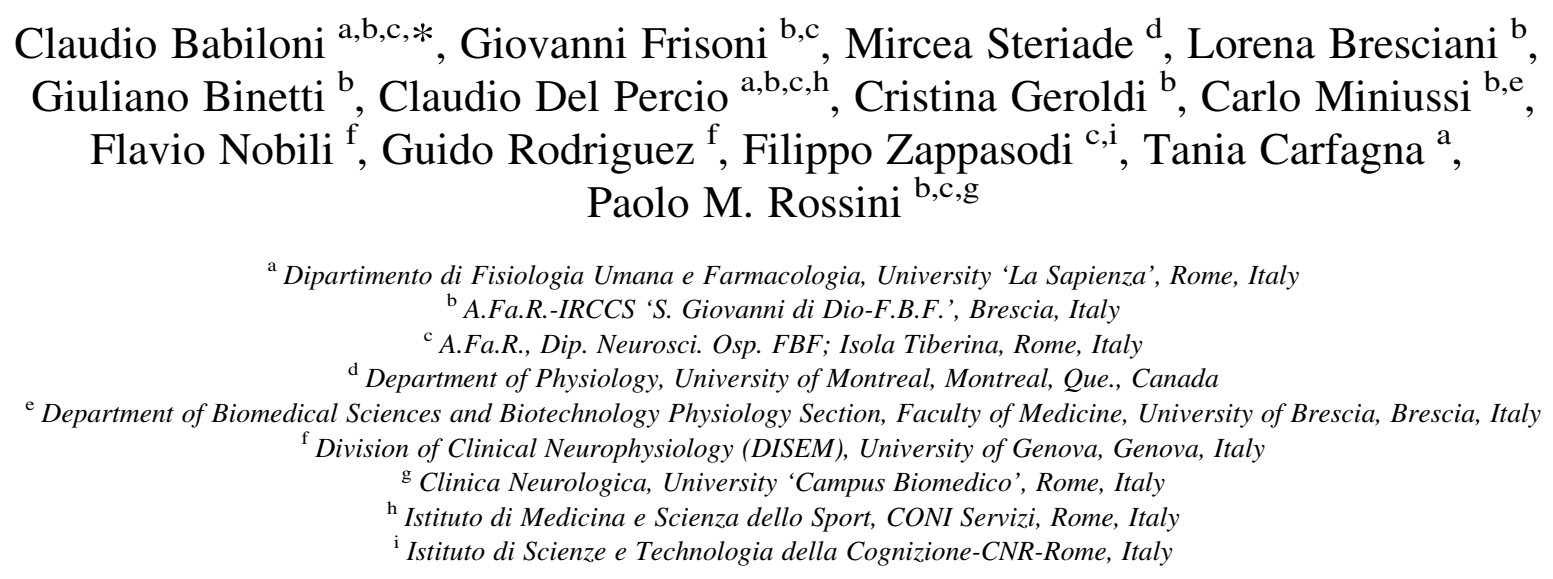

Accepted 28 January 2006

\begin{abstract}
Objective: A relationship between brain atrophy and delta rhythmicity (1.5-4 Hz) has been previously explored in Alzheimer's disease (AD) subjects [Fernandez A, Arrazola J, Maestu F, Amo C, Gil-Gregorio P, Wienbruch C, Ortiz T. Correlations of hippocampal atrophy and focal low-frequency magnetic activity in Alzheimer disease: volumetric MR imaging-magnetoencephalographic study. Am J Neuroradiol. 2003 24(3):481-487]. In this study, we tested the hypothesis that such a relationship does exist not only in AD patients but also across the continuum of subjects with mild cognitive impairment (MCI) and AD.

Methods: Resting, eyes-closed EEG data were recorded in $34 \mathrm{MCI}$ and 65 AD subjects. EEG rhythms of interest were delta (2-4 Hz), theta (4-8 Hz), alpha $1(8-10.5 \mathrm{~Hz})$, alpha $2(10.5-13 \mathrm{~Hz})$, beta $1(13-20 \mathrm{~Hz})$, and beta $2(20-30 \mathrm{~Hz})$. EEG cortical sources were estimated by LORETA. Cortical EEG sources were correlated with MR-based measurements of lobar brain volume (white and gray matter).

Results: A negative correlation was observed between the frontal white matter and the amplitude of frontal delta sources (2-4 Hz) across MCI and AD subjects.

Conclusions: These results confirmed for the first time the hypothesis that the sources of resting delta rhythms (2-4 Hz) are correlated with lobar brain volume across MCI and AD subjects.

Significance: The present findings support, at least at group level, the 'transition hypothesis' of brain structural and functional continuity between MCI and AD.

(C) 2006 International Federation of Clinical Neurophysiology. Published by Elsevier Ireland Ltd. All rights reserved.
\end{abstract}

Keywords: Mild cognitive impairment (MCI); Alzheimer's disease (AD); Electroencephalography (EEG); Magnetic resonance imaging (MRI); Low resolution brain electromagnetic tomography (LORETA)

\footnotetext{
* Corresponding author. Address: Dipartimento di Fisiologia Umana e Farmacologia, Università degli Studi di Roma 'La Sapienza', P.le Aldo Moro 5, 00185 Rome, Italy. Tel.: +3906 49910989; fax: +3906 49910917.

E-mail address: claudio.babiloni@uniroma1.it (C. Babiloni).

$U R L:$ http://hreeg.ifu.uniroma1.it/ (C. Babiloni).
} 


\section{Introduction}

Mild cognitive impairment (MCI) is a clinical state between elderly normal cognition and dementia featuring memory complaints and cognitive impairment on neuropsychological testing, but no dementia (Flicker et al., 1991; Petersen et al., 1995, 2001). MCI is regarded a precursor of Alzheimers' disease (AD) (Arnaiz and Almkvist, 2003; Galluzzi et al., 2001; Scheltens et al., 2002), since recent studies have shown a high rate of progression to $\mathrm{AD}$ (Bachman et al., 1993; Gao et al., 1998; Petersen et al., 2001). In cognitively intact elders, the incidence of AD ranges from 0.17 to $3.86 \%$ (Frisoni et al., 2004; Petersen et al., 2001), while in patients with MCI it is much higher, ranging from 6 to 25\% (Petersen et al., 2001). However, the 'transition' hypothesis is challenged by observations indicating that not all MCI patients deteriorate over time (Bennett et al., 2002; Larrieu et al., 2002), as AD cumulative incidence rates ranged from 40 to $60 \%$ (Bennett et al., 2002; Fisk et al., 2003; Larrieu et al., 2002).

MCI patients that will convert to dementia are the ideal target of preventive therapeutic strategies (Braak and Braak, 1991; Rogers et al., 1996; Small et al., 1995) and might be identified with functional and structural imaging techniques. Previous studies have successfully investigated the electrophysiological substrate of AD. In mild AD, electroencephalographic (EEG) rhythms differ from normal elderly (Nold) and vascular dementia subjects, $\mathrm{AD}$ patients featuring an excess of delta $(0-4 \mathrm{~Hz})$ and a significant decrement of posterior alpha rhythms $(8-12 \mathrm{~Hz}$; Babiloni et al., 2004a; Dierks et al., 1993, 2000; Huang et al., 2000; Jeong, 2004; Ponomareva et al., 2003). EEG rhythm abnormalities in dementia have been associated with altered regional cerebral blood flow (rCBF)/metabolism and cognitive function (Celsis et al., 1990; Ihl et al., 1989; Jeong, 2004; Joannesson et al., 1977; Nobili et al., 2002a,b; Passero et al., 1995; Rodriguez et al., 1998, 1999a,b; Sheridan et al., 1988; Sloan et al., 1995; Szelies et al., 1992). Similarly, MCI subjects have shown a decrease of alpha power when compared to normal elderly subjects (Babiloni et al., 2006a; Koenig et al., 2005; Zappoli et al., 1995; Elmstahl and Rosen, 1997; Huang et al., 2000; Jelic et al., 2000).

Several other studies with magnetic resonance imageign (MRI) have demonstrated that structural changes of brain volume characterize AD (de Leon et al., 2004). Algorithms denoting gray matter loss or white matter changes (voxelbased morphometry, VBM) have shown medial temporal lobe atrophy as well as temporoparietal atrophy in mildly to moderately severe AD patients (Baron et al., 2001; Frisoni et al., 2002; Ohnishi et al., 2001; Rombouts et al., 2000). In MCI subjects, these algorithms have also detected atrophy in the medial temporal lobe, temporal neocortex, superior parietal lobule, anterior cingulate gyrus, and thalamus (Chetelat et al., 2002; Pennanen et al., 2005). Other techniques of structural MRI analysis have corroborated the finding of medial temporal atrophy in MCI subjects, which is also the most common MRI finding in AD patients (Testa et al., 2004; Wolf et al., 2003). Based on these data, one can speculate that the aforementioned changes of EEG rhythms in MCI and $\mathrm{AD}$ are related to loss of neurons in limbic and neocortical regions. Indeed, the bilateral reduction of hippocampal and entorhinal volumes of $\mathrm{AD}$ subjects has been recently correlated with an increment of cortical delta rhythms (Fernandez et al., 2003).

To the best of our knowledge, the relationship between brain atrophy and EEG rhythms has not been explored in MCI subjects. In this study, we test the hypothesis that such a relationship does exist not only in $\mathrm{AD}$ patients but across the continuum between $\mathrm{MCI}$ and $\mathrm{AD}$, in line with the idea that $\mathrm{MCI}$ is often due to underlying neurodegenerative processes. Cortical sources of resting EEG rhythms in MCI and mild $\mathrm{AD}$ subjects were estimated by low-resolution brain electromagnetic tomography (LORETA; Pascual Marqui et al., 1994, 1999, 2002), which has been successfully used in recent studies on physiological and pathological aging (Babiloni et al., 2004a, 2005a, 2006a,b; Dierks et al., 2000). The main statistical analysis aimed at evaluating two working hypotheses. A preliminary control hypothesis was that lobar EEG sources as revealed by the LORETA solutions had amplitude sensitivity to the cognitive status of recruited subjects. The experimental hypothesis stated a correlation between lobar brain volumes and EEG sources across MCI and mild AD subjects.

\section{Methods}

We have extensively described in recent papers part of the procedures (EEG recordings and LORETA analysis) pertinent to the current study as well as a description of the potential meaning of cortical rhythms in aging (Babiloni et al., 2004a, 2005a, 2006a). The previous studies aimed at analyzing (i) the distributed EEG sources specific to mild $\mathrm{AD}$ as compared to vascular dementia or normal aging (Babiloni et al., 2004a); (ii) the distributed EEG sources during physiological aging (Babiloni et al., 2005a); and (iii) the cortical EEG rhythms change across Nold, MCI and mild $\mathrm{AD}$ subjects as a function of the global cognitive level (Babiloni et al., 2006a). As an original contribution, the current study focused on the relationship between distributed EEG sources and lobar volume (MRI) in MCI and mild AD subjects. For the convenience of readers, here we describe the EEG methodology although reported in the mentioned previous papers.

\subsection{Subjects and diagnostic criteria}

Sixty-five MCI subjects and 28 mild AD patients were enrolled. We also recruited 34 cognitively normal elderly (Nold) subjects as controls. Local institutional ethics committees approved the study. All experiments were performed with the informed and overt consent of each 
participant or caregiver, in line with the Code of Ethics of the World Medical Association (Declaration of Helsinki) and the standards established by the Author's Institutional Review Board.

The present inclusion and exclusion criteria for MCI were based on previous seminal studies (Albert et al., 1991; Devanand et al., 1997; Flicker et al., 1991; Petersen et al., 1995, 1997, 2001; Rubin et al., 1989; Zaudig, 1992). These criteria aimed at selecting elderly persons with objective cognitive deficits, especially in the memory domain, who did not meet criteria for a diagnosis of dementia or AD. The inclusion criteria for the MCI subjects were the following: (i) objective memory impairment on neuropsychological evaluation, as defined by performances $\geq 1.5$ standard deviation below the mean value of age and educationmatched controls for a test battery including Busckhe-Fuld and Memory Rey tests; (ii) normal activities of daily living as documented by the history and evidence of independent living; and (iii) clinical dementia rating score of 0.5 . The exclusion criteria for MCI were as follows: (i) mild AD, as diagnosed by the procedures described below; (ii) evidence of concomitant dementia such as frontotemporal, vascular dementia, reversible dementias (including pseudo-depressive dementia), fluctuations in cognitive performance, and/ or features of mixed dementias; (iii) evidence of concomitant extra-pyramidal symptoms; (iv) clinical and indirect evidence of depression as revealed by Geriatric Depression Scale scores higher than 13; (v) other psychiatric diseases, epilepsy, drug addiction, alcohol dependence, and use of psychoactive drugs including acetylcholinesterase inhibitors or other drugs enhancing brain cognitive functions; and (vi) current or previous uncontrolled or complicated systemic diseases (including diabetes mellitus) or traumatic brain injuries. In one of the research units (Brescia), the subjects were recruited within an observational study on the natural history of MCI.

Probable AD was diagnosed according to NINCDSADRDA (McKhann et al., 1984). Patients underwent general medical, neurological and psychiatric assessments and were also rated with a number of standardized diagnostic and severity instruments that included MMSE (Folstein et al., 1975), Clinical Dementia Rating Scale (Hughes et al., 1982), Geriatric Depression Scale (Yesavage et al., 1983), Hachinski Ischemic Scale (Rosen et al., 1980), and Instrumental Activities of Daily Living Scale (Lawton and Brodie, 1969). Neuroimaging diagnostic procedures
(CT or MRI) and complete laboratory analyses were carried out to exclude other causes of progressive or reversible dementias, in order to have a homogenous mild AD patient sample. The exclusion criteria included, in particular, any evidence of (i) frontotemporal dementia diagnosed according to criteria of Lund and Manchester Groups (1994); (ii) vascular dementia as diagnosed according to NINDSAIREN criteria (Roman et al., 1993); (iii) extra-pyramidal syndromes; (iv) reversible dementias (including pseudodementia of depression); and (v) Lewy body dementia according to the criteria by McKeith et al. (1999). The detection of the vascular component in dementia and MCI was accounted based on previous theoretical guidelines from our network (Frisoni et al., 1995; Galluzzi et al., 2005). Of note, benzodiazepines, antidepressant and/or antihypertensive drugs were withdrawn for about $24 \mathrm{~h}$ before the EEG recordings. The mild AD patients were recruited within an ongoing study on structural and cerebrovascular brain features of persons with dementia.

The control Nold group was recruited in order to ascertain that EEG rhythmic activity changed across the continuum of Nold, MCI, and mild AD subjects, a prerequisite for further analyses based on EEG data. Indeed, it allowed to verify whether cortical EEG rhythms differed in the MCI and AD subjects of the present study when compared to Nold subjects. The Nold subjects were recruited mostly among non-consanguineous patients' relatives. All Nold subjects underwent physical and neurological examinations as well as cognitive screening. Subjects affected by chronic systemic illnesses, subjects receiving psychoactive drugs, and subjects with a history of present or previous neurological or psychiatric disease were excluded. All Nold subjects had a GDS score lower than 14 (no depression).

For a preliminary validation of the EEG source analysis, the MCI subjects were subdivided in two sub-groups based on a cut-off of 27 at MMSE score: MCI- (35 subjects, MMSE $\geq 27)$ and MCI + (30 subjects, $22<$ MMSE $<27)$. That criterion allowed the formation of two sub-groups of MCI subjects with similar personal features but different cognitive status. The control hypothesis was that EEG sources differed in line with the cognitive status across Nold, MCI - , MCI + , and mild AD. Table 1 summarizes the relevant demographic and clinical data of the recruited Nold $(N=34)$, MCI $-(N=30)$, MCI $+(N=35)$, and mild $\mathrm{AD}(N=28)$ subjects. Of note, age, education and gender

Table 1

Demographic and neuropsychological data of interest of normal elderly (Nold), mild cognitive impairment (MCI), and mild Alzheimer's disease (AD) subjects

\begin{tabular}{llll}
\hline & Nold & MCI - & MCI+ \\
\hline$N$ & 34 & 35 & 30 \\
Age (years) & $68.8( \pm 1.7 \mathrm{SE})$ & $67.8( \pm 1.5 \mathrm{SE})$ & $72( \pm 0.8 \mathrm{SE})$ \\
Gender (F/M) & $17 \mathrm{~F} / 17 \mathrm{M}$ & $28 \mathrm{~F} / 7 \mathrm{M}$ & $76.6( \pm 1.3 \mathrm{SE})$ \\
MMSE & $29( \pm 0.2 \mathrm{SE})$ & $28.1( \pm 0.2 \mathrm{SE})$ & $15 \mathrm{~F} / 15 \mathrm{M}$ \\
Education (years) & $9.4( \pm 0.9 \mathrm{SE})$ & $6.6( \pm 0.6 \mathrm{SE})$ & $25( \pm 0.2 \mathrm{SE})$ \\
\hline
\end{tabular}

Of note, MCI subjects were subdivided in two sub-groups: MCI - (mini mental state evaluation, MMSE $\geq 27)$ and MCI $+(22<\mathrm{MMSE}<27)$. 
were used as covariates in the statistical evaluation of the cortical sources of EEG rhythms.

\subsection{Magnetic resonance imaging (MRI)}

High-resolution sagittal T1-weighted volumetric MRIs were acquired in MCI and mild AD subjects using a $1.5 \mathrm{~T}$ Magnetom scanner (Siemens, Erlangen, Germany), with a gradient echo 3D technique: $\mathrm{TR}=10 \mathrm{~ms}, \mathrm{TE}=4 \mathrm{~ms}, \mathrm{TI}=$ $300 \mathrm{~ms}$, flip angle $=10^{\circ}$, field of view $=250 \mathrm{~mm}$, acquisition matrix $160 \times 256$, and a slice thickness of $1.3 \mathrm{~mm}$.

The MRIs were analyzed by Statistical Parametric Mapping software (SPM99, www.fil.ion.ucl.ac.uk/spm). The images were pre-processed following an optimized protocol (Good et al., 2001), which included (i) generation of customized template, (ii) generation of customized prior probability maps, and (iii) the following voxel-based morphometry (VBM) steps: normalization of the original MR images; segmentation of normalized images into gray matter (GM) and white matter (WM); cleaning and modulation of GM and WM images; and smoothing of modulated images. In order to calculate GM and WM volumes, a customized program (SPM 99) was applied to GM and WM modulated images. In particular, the modulated images were 3D matrices where the intensity of each voxel was proportional to GM, WM, and cerebrospinal fluid (CSF) volume within each voxel. The program calculated volumes by summing up the number of voxels of the modulated images and multiplying it times the voxel's volume. Total intracranial volume (TIV) was computed as the sum of GM, WM and CSF volumes.

Lobar volumes were defined by applying to the modulated images binary lobar masks, which were previously traced along the boundaries of the frontal, temporal, parietal-occipital lobes. The lobar boundaries for the binary masks were defined by manually tracing coronal slices according to conventional segmentation already used with different techniques (De Carli et al., 1992, 1994). All lobes were traced on aligned coronal slices proceeding from anterior to posterior. According to this conventional segmentation, the first region of interest (ROI) for both frontal and temporal lobes was traced on the slices where the brain matter could initially be appreciated and the last ROIs on the slice where the sylvian acqueduct appeared in its whole length. The mask for the parietal lobe started at the immediately successive slice, and included all visual brain. As both the calcarine and the parieto-occipital sulci were clearly appreciable in the same slice, all visible brain was traced as belonging to the occipital lobe. As to the cerebellar mask, attention was paid to exclude segmental structures (Pierson et al., 2002).

The correlation analysis among lobar brain volume indexes (GM, WM) and corresponding lobar brain EEG sources imposed a limitation in the number of ROIs, to reduce the risk of statistical alpha 1 errors during the statistical analysis. Therefore, we just considered 3 macroregions for our correlation analysis at lobar level, namely frontal, parietal-occipital, and temporal ROI. Of note, the lobar volumes of these 3 ROI were normalized respect to the TIV. Therefore, the lobar volumes lost the original physical dimension and were represented by an arbitrary unit scale.

Finally, we were unable to recruit a sufficient number of Nold subjects for the MRI data acquisition, since many of them refused the MRI recording. This made it not viable the analysis of the correlation between lobar brain volume indexes and corresponding lobar brain EEG sources in Nold subjects compared to MCI and mild AD subjects. It should be considered as an important issue for future research.

\subsection{EEG recordings}

EEG data was recorded by specialized clinical units in Nold, MCI, and mild AD subjects at resting state (eyesclosed). EEG recordings were performed $(0.3-70 \mathrm{~Hz}$ bandpass) from 19 electrodes positioned according to the International 10-20 System (i.e. Fp1, Fp2, F7, F3, Fz, F4, F8, T3, C3, Cz, C4, T4, T5, P3, Pz, P4, T6, O1, O2). A specific reference electrode was not imposed to all recording units of this multi-centric study, since preliminary data analysis and LORETA source analysis were carried out after EEG data were re-referenced to a common average reference. To monitor eye movements, the horizontal and vertical electrooculogram $(0.3-70 \mathrm{~Hz}$ bandpass) was also collected. All data were digitized in continuous recording mode (5 min of EEG; $128-256 \mathrm{~Hz}$ sampling rate, the sampling rate being fixed in each recording research unit of this multi-centric study. In all subjects, the EEG recordings were performed in the late morning. In order to keep constant, the level of vigilance, an operator controlled on-line the subject and the EEG traces. He verbally alerted the subject any time there were signs of behavioral and/or EEG drowsiness.

The duration of the EEG recording ( $5 \mathrm{~min}$ ) allowed the comparison of the present results with several previous $\mathrm{AD}$ studies using either EEG recording periods shorter than 5 min (Babiloni et al., 2004a,b; Buchan et al., 1997; Pucci et al., 1999; Rodriguez et al., 2002; Szelies et al., 1999) or shorter than $1 \mathrm{~min}$ (Dierks et al., 1993; 2000). Longer resting EEG recordings in $\mathrm{AD}$ patients would have reduced data variability but would have increased the possibility of EEG 'slowing' because of reduced vigilance and arousal.

The recorded EEG data were analyzed and fragmented off-line in consecutive epochs of $2 \mathrm{~s}$. For standardization purposes, preliminary analysis of all data was centralized in one research unit. The EEG epochs with ocular, muscular, and other types of artifact were preliminary identified by a computerized automatic procedure. EEG epochs with sporadic blinking artifacts (less than $15 \%$ of the total) were corrected by an autoregressive method (Moretti et al., 2003). Two independent experimenters manually confirmed the EEG segments accepted for further analysis. Of note, they 
were blind to the diagnosis at the time of the EEG data analysis. Indeed, the diagnosis required the integration of many other clinical and psychometric parameters and was formulated several weeks after the EEG data recording and analysis.

\subsection{Spectral analysis of the EEG data}

A digital FFT-based power spectrum analysis (Welch technique, Hanning windowing function, no phase shift) computed power density of the EEG rhythms with $0.5 \mathrm{~Hz}$ frequency resolution. The following standard band frequencies were studied: delta $(2-4 \mathrm{~Hz})$, theta $(4-8 \mathrm{~Hz})$, alpha $1(8-$ $10.5 \mathrm{~Hz})$, alpha $2(10.5-13 \mathrm{~Hz})$, beta $1(13-20 \mathrm{~Hz})$, and beta $2(20-30 \mathrm{~Hz})$. These band frequencies were chosen averaging those used in previous relevant EEG studies on dementia (Besthorn et al., 1997; Chiaramonti et al., 1997; Jelic et al., 1996; Leuchter et al., 1993; Rodriguez et al., 1999a,b) and have been successfully used in recent studies on AD of this Consortium (Babiloni et al., 2004a,b, 2005a, $2006 a, b)$. Sharing of a frequency bin by two contiguous bands is a widely accepted procedure (Besthorn et al., 1997; Cook and Leuchter, 1996; Holschneider et al., 1999; Jelic et al., 1996; Kolev et al., 2002; Leuchter et al., 1993; Nobili et al., 1998; Pucci et al., 1997). Furthermore, this fits the theoretical consideration that near EEG rhythms may overlap at their frequency borders (Babiloni et al., 2004c-g, 2005b; Klimesch, 1996, 1999; Klimesch et al., 1997, 1998).

Choice of the fixed EEG bands did not account for individual alpha frequency (IAF) peak, defined as the frequency associated with the strongest EEG power at the extended alpha range (Klimesch, 1999). However, this should not affect the results, since most of the subjects had IAF peaks within the alpha 1 band $(8-10.5 \mathrm{~Hz})$. In particular, mean IAF peak was $9 \mathrm{~Hz}( \pm 0.2$ standard error, SE) in Nold subjects, $9.3 \mathrm{~Hz}( \pm 0.2 \mathrm{SE})$ in MCI - subjects, $9.4 \mathrm{~Hz}( \pm 0.2 \mathrm{SE})$ in MCI + subjects, and $8.6 \mathrm{~Hz}( \pm 0.3 \mathrm{SE})$ in mild AD patients. To control for the effect of IAF on the EEG comparisons between these 4 groups, the IAF peak was used as a covariate (together with age, education and gender) for further statistics.

We could not use narrow frequency bands for beta 1 $(13-20 \mathrm{~Hz})$ and beta $2(20-30 \mathrm{~Hz})$, because of the variability of beta peaks in the power spectra. Therefore, LORETA results for the beta bands could suffer from sensitivity limitations of EEG spectral analyses for large bands (Szava et al., 1994).

The analysis of the delta band was restricted to $2-4 \mathrm{~Hz}$ for homogeneity with previously quoted field literature and to avoid the residual effects of uncontrolled head movements especially in AD patients. However, previous evidence has shown that delta band contains two distinct oscillations. There are slow oscillations around $1 \mathrm{~Hz}$ (Achermann and Borbely, 1997; Amzica and Steriade, 1997) and oscillations at $2-3 \mathrm{~Hz}$ (Massimini et al., 2004). For this reason, we performed a separate control analysis for the study of the slow component of the delta rhythms, namely at $0.5-1.5 \mathrm{~Hz}$.

\subsection{Cortical source analysis of the EEG rhythms by LORETA}

As aforementioned, the popular LORETA technique was used for the EEG source analysis as provided at http://www. unizh.ch/keyinst/NewLORETA/LORETA01.htm (PascualMarqui et al., 1994, 1999, 2002). LORETA is a functional imaging technique belonging to a family of linear inverse solution procedures (Valdes et al., 1998) modeling 3D distributions of EEG sources (Pascual-Marqui et al., 2002). With respect to the dipole modeling of cortical sources, no a priori decision of the dipole position is required by the investigators in LORETA estimation. In a previous review paper, it has been shown that LORETA was quite efficient when compared to other linear inverse algorithms like minimum norm solution, weighted minimum norm solution or weighted resolution optimization (Pascual-Marqui et al., 1999). Furthermore, independent validation of the LORETA solutions has been provided by recent studies (Phillips et al., 2002; Yao and He, 2001). Finally, LORETA has been successfully used in recent EEG studies on pathological aging (Babiloni et al., 2004a, 2005b; Dierks et al., 2000). LORETA computes 3D linear solutions (LORETA solutions) for the EEG inverse problem within a 3-shell spherical head model including scalp, skull, and brain compartments. The brain compartment is restricted to the cortical gray matter/hippocampus of a head model coregistered to the Talairach probability brain atlas and digitized at the Brain Imaging Center of the Montreal Neurological Institute (Talairach and Tournoux, 1988). This compartment includes 2394 voxels ( $7 \mathrm{~mm}$ resolution), each voxel containing an equivalent current dipole.

LORETA can be used from EEG data collected by low spatial sampling of 10-20 system (19 electrodes) when cortical sources are estimated from resting EEG rhythms. In fact, several previous studies have shown that these rhythms are generated by largely distributed cortical sources that can be accurately investigated by standard 10-20 system and LORETA (Anderer et al., 2000, 2003, 2004; Babiloni et al., 2004a, 2005a, 2006a,b; Isotani et al., 2001; Laufer and Pratt, 2003a,b; Mulert et al., 2001; Veiga et al., 2003; Winterer et al., 2001).

LORETA solutions consisted of voxel $z$-current density values able to predict EEG spectral power density at scalp electrodes. It is widely accepted the idea that LORETA is a reference-free method of EEG analysis, in that one obtains the same LORETA source distribution for EEG data referenced to any reference electrode including common average. A normalization of the data was obtained by normalizing the LORETA current density at each voxel with the LORETA power density averaged across all frequencies $(0.5-45 \mathrm{~Hz})$ and across all 2394 voxels of the brain volume. After the normalization, the LORETA solutions lost the 
original physical dimension and were represented by an arbitrary unit scale. This procedure reduced inter-subjects variability and was used in previous EEG studies (Babiloni et al., 2004a, 2005a, 2006a,b). The general procedure fitted the LORETA solutions in a Gaussian distribution and reduced inter-subject variability (Leuchter et al., 1993; Nuwer, 1988). Other methods of normalization using the principal component analysis are effective for estimating the subjective global factor scale of the EEG data (Hernández et al., 1994). These methods are not available in the LORETA package, so they were not used in this study.

Solutions of the EEG inverse problem are underdetermined and ill conditioned when the number of spatial samples (electrodes) is lower than that of the unknown samples (current density at each voxel). To account for that, the cortical LORETA solutions predicting scalp EEG spectral power density were regularized to estimate distributed rather than punctual EEG source patterns (Pascual-Marqui et al., 1994, 1999, 2002). In line with the low spatial resolution of the LORETA technique and with the lobar volume measurements, we collapsed LORETA solutions at frontal, parietal-occipital, and temporal ROIs of the brain model coded into the Talairach space. The Brodmann areas for each ROI are listed in Table 2.

The main advantage of the regional analysis of LORETA solutions was that our modeling could disentangle the EEG rhythms of contiguous cortical areas. For example, the EEG rhythms of the parieto-occipital source were disentangled with respect to those of the contiguous temporal sources, etc. This was made it possible by the fact that LORETA solves the linear inverse problem by taking into account the well-known effects of the head as a volume conductor. With respect to other procedures of data reduction, this type of lobar approach may represent an important reference for multi-modal comparisons with structural and functional neuroimaging methods (SPECT, PET, surface EEG/MEG topography). Finally, it can be stated that the present approach represents a clear methodological improvement compared to the EEG spectral analyses at surface electrodes. Indeed, the EEG potentials collected at each scalp electrode are strongly affected by head volume conductor effects. For example, the parieto-occipital electrodes collect scalp EEG potentials generated not only from the parieto-occipital cortex but also from temporal cortices, due to head volume conductor effects.

The LORETA technique including a template head model has been repeatedly used in the investigation of EEG rhythms

Table 2

Brodmann areas included in the cortical regions of interest (ROIs) of the present study

\section{Frontal}

Parietal-occipital

Temporal

$8,9,10,11,44,45,46,47$

$5,7,17,18,19,30,39,40,43$

$20,21,22,37,38,41,42$

LORETA solutions were collapsed in frontal, parietal-occipital, and temporal ROIs. in physiological and pathological aging (Anderer et al., 1998a,b, 2003; Babiloni et al., 2004a; Cincotti et al., 2004a; Dierks et al., 2000; Goforth et al., 2004; Huang et al., 2002; Saletu et al., 2002). This was probably due to the fact that the spatial smoothing of the LORETA solutions (resolution in centimeters) and its head template could reliably take into account the slight change in the cortical volume (resolution in millimeters) present in the mild stages of $\mathrm{AD}$.

\subsection{Statistical analysis of lobar brain volumes}

A statistical analysis evaluated whether the lobar brain volume indexes of GM and WM differed among MCI-, $\mathrm{MCI}+$, and mild $\mathrm{AD}$ subjects. To this aim, the lobar brain volumes from $\mathrm{MCI}-, \mathrm{MCI}+$ and mild $\mathrm{AD}$ subjects were used as an input for two ANOVA analyses for WM and GM volumes, respectively. Subjects' age served as covariate. Indeed, previous papers have shown that the white matter decreased with age (Bartzokis et al., 2001; Meier-Ruge et al., 1992). Correction of the degrees of freedom was made with the Greenhouse-Geisser procedure. The two ANOVA analyses used the factors Group (MCI-, MCI+, mild AD; independent analysis) and ROI (frontal, parietal-occipital, temporal).

\subsection{Statistical analysis of lobar LORETA solutions}

As a aforementioned, the main statistical analysis aimed at evaluating two working hypotheses. The first hypothesis was that lobar EEG sources as revealed by the LORETA solutions had amplitude sensitive to the cognitive status of Nold, MCI, MCI+, and mild AD subjects. The confirmation of this hypothesis would validate the procedures relative to subjects' recruitment and EEG data analysis. To this aim, the lobar LORETA solutions from Nold, MCI - , MCI + and mild AD subjects were used as an input for an ANOVA analysis. Subjects' age, education, gender and IAF peak served as covariates. Mauchly's test evaluated the sphericity assumption. Correction of the degrees of freedom was made with the Greenhouse-Geisser procedure. The ANOVA analysis used the factors Group (Nold, MCI-, MCI +, mild AD; independent analysis), Band (delta, theta, alpha 1, alpha 2, beta 1, beta 2), and ROI (frontal, parietal-occipital, temporal). The first hypothesis would be confirmed by the following 3 statistical results: (i) a statistical ANOVA effect including the factor Group $(P<0.05)$; (ii) a post hoc test indicating statistically significant differences of the LORETA solutions with the pattern mild $\mathrm{AD} \neq$ Nold, $\mathrm{MCI}-$, and $\mathrm{MCI}+$ (Duncan test, $P<0.05$ ); (iii) a statistically significant correlation in all subjects as a single group among the MMSE score and the lobar LORETA solutions fitting the pattern mild $\mathrm{AD} \neq$ Nold, $\mathrm{MCI}-$, MCI + (Spearman test; Bonferroni corrected, $P<0.05$ ).

The second hypothesis regarded the correlation between lobar brain volumes and EEG sources in MCI and mild AD subjects. This hypothesis would be confirmed by statistically significant correlations (Pearson test, $P<0.01$ ) 
among lobar brain volumes and the amplitude of the lobar LORETA solutions at the corresponding ROI (note the LORETA solutions were those fitting the pattern mild $\mathrm{AD} \neq$ Nold, $\mathrm{MCI}-, \mathrm{MCI}+$ and having a statistically significant correlation with the MMSE score).

In addition, separate control analyses were performed on slow component of the delta rhythms (i.e. $0.5-1.5 \mathrm{~Hz}$ ), on sub-groups of subjects paired as personal variables, and on individual alpha rhythms (see Section 3).

\section{Results}

\subsection{Topography of the EEG cortical sources as estimated by LORETA}

For illustrative purposes, Fig. 1 maps the grand average of the LORETA solutions (i.e. relative $z$-current density at cortical voxels) modeling the distributed EEG sources for delta, theta, alpha 1 , alpha 2 , beta 1 , and beta 2 bands in Nold, MCI - , MCI + and mild AD groups. The Nold group presented alpha 1 sources with the maximal values of amplitude distributed in parieto-occipital regions. Delta, theta and alpha 2 sources had moderate amplitude values when compared to alpha 1 sources. Finally, beta 1 and beta 2 sources were characterized by lowest amplitude values. Compared to Nold group, both $\mathrm{MCI}-$ and $\mathrm{MCI}+$ groups showed a decrease in amplitude of the parieto-occipital and temporal alpha 1 sources. This was slightly stronger in $\mathrm{MCI}+$ than $\mathrm{MCI}$ - group. With respect to Nold, MCI, and $\mathrm{MCI}+$ groups, mild AD group showed an amplitude increase of widespread delta sources, along with a strong amplitude reduction of parieto-occipital alpha 1 sources. Finally, there were relatively high values of the theta sources in mild AD group.

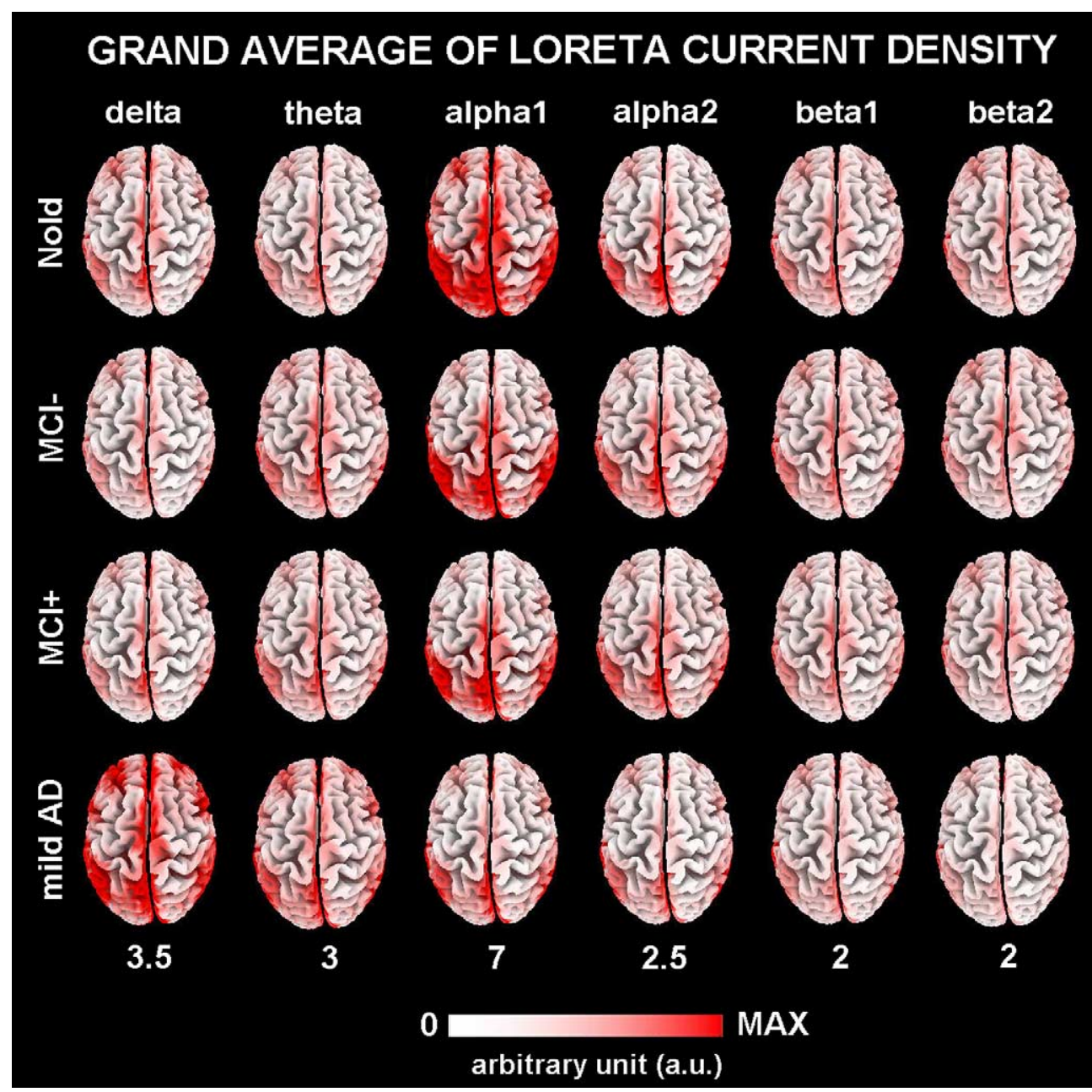

Fig. 1. Grand average of LORETA solutions (i.e. normalized relative current density at the cortical voxels) modeling the distributed EEG sources for delta, theta, alpha 1, alpha 2, beta 1, and beta 2 bands in Nold, MCI - (MMSE $\geq 27)$, MCI $+(22<$ MMSE $<27)$, and mild AD groups. The left side of the maps (top view) corresponds to the left hemisphere. Legend: LORETA, low resolution brain electromagnetic tomography. Color scale: all power density estimates were scaled based on the averaged maximum value (i.e. alpha 1 power value of occipital region in Nold). The maximal value of power density is reported under each column. 


\subsection{Statistical analysis of the lobar brain volumes}

Fig. 2 provides the information of lobar brain volumes (frontal, temporal and parietal-occipital) of WM and GM for $\mathrm{MCI}-, \mathrm{MCI}+$ and mild $\mathrm{AD}$ subjects. The ANOVA analysis for WM volumes showed a statistical interaction $(F(4,180)=9.5 ; \mathrm{MSe}=49.6 ; P<0.0001)$ among the factors Group (MCI-, MCI+, mild AD) and ROI (frontal, parietal-occipital, temporal). The planned Duncan post hoc testing showed that the amplitude of frontal and parietal-occipital WM was lower in mild AD compared to $\mathrm{MCI}-(P<0.00002)$ and $\mathrm{MCI}+\operatorname{group}(P<0.00002)$. The ANOVA analysis for GM volumes showed neither

\section{LOBAR BRAIN VOLUMES}
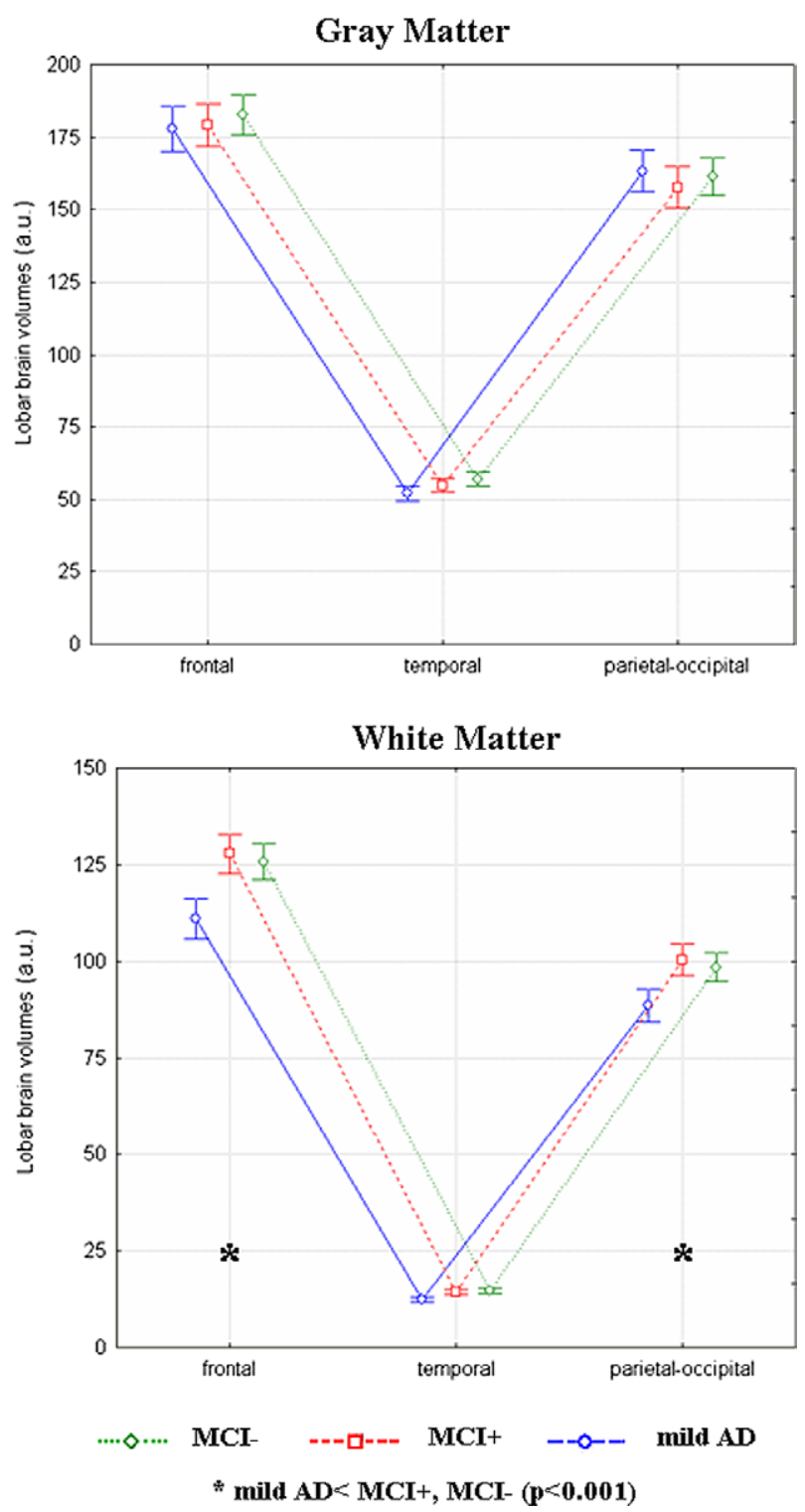

Fig. 2. Lobar brain volumes of white matter (WM) and gray matter (GM) for $\mathrm{MCI}-, \mathrm{MCI}+$ and mild $\mathrm{AD}$ subjects. The following lobar volumes were considered: frontal, parietal-occipital, and temporal. a statistical main effect for factor Group $(P>0.4)$ nor a statistical interaction between Group and ROI $(P>0.15)$.

\subsection{Statistical analysis of the EEG cortical sources estimated by LORETA}

Kolmogorov-Smirnov test was used to evaluated the Gaussian distribution of the normalized regional LORETA solutions in Nold, MCI-, MCI + and AD subjects. The results showed that almost all normalized regional LORETA solutions presented a Gaussian distribution in the 4 groups $(P>0.1)$. The only violations of the Gaussianity were observed for the LORETA solutions relative to parietal-occipital theta (in MCI + subjects) and frontal alpha 2 (in AD subjects) $(P<0.05)$. These LORETA solutions were not further considered for the ANOVA analysis.

Fig. 3 shows mean lobar LORETA solutions (distributed EEG sources) relative to a statistical ANOVA interaction $(\mathrm{F}(30,1230)=4.4 ; \mathrm{MSe}=0.78 ; P<0.0001)$ among the factors Group (Nold, MCI-, MCI+, mild AD), Band (delta, theta, alpha 1, alpha 2 , beta 1 , beta 2 ), and ROI (frontal, parietal-occipital, temporal). In the figure, the lobar LORETA solutions had the shape of EEG relative power spectra. Notably, profile and magnitude of these spectra in Nold, MCI - , MCI + and mild AD groups differed across diverse cortical macro-regions, thus supporting the idea that scalp EEG rhythms are generated by a distributed pattern of cortical sources. The planned post hoc testing showed that the source pattern mild $\mathrm{AD} \neq$ Nold, $\mathrm{MCI}-, \mathrm{MCI}+$ was fitted by the following 5 lobar LORETA solutions: parietaloccipital and temporal alpha 1 sources $(P<0.000009$ to $P<0.000001)$ as well as frontal, parietal-occipital, and temporal delta sources $(P<0.002$ to $P<0.000001)$. Furthermore, the parietal-occipital and temporal alpha 1 sources showed stronger amplitude in Nold compared to MCI - group $(P<0.02$ to $P<0.000003)$ and in $\mathrm{MCI}-$ compared to MCI + group $(P<0.02$ to $P<0.007)$.

These 5 lobar LORETA solutions were correlated with the MMSE score in all subjects as a whole group (Spearman test; Bonferroni correction for 5 repetitions of the test gave the threshold $P<0.01$ to obtain the Bonferroni corrected $P<0.05)$. The MMSE score negatively correlated with the frontal $(r=-0.22, P=0.01)$ and temporal $(r=-0.26$, $P=0.003)$ delta sources. Furthermore, the MMSE score positively correlated with the parietal-occipital $(r=0.22$, $P=0.01$ ) alpha 1 sources. These 3 lobar LORETA sources were considered as specifically sensitive to pathological aging across the recruited Nold, MCI, and mild AD subjects. Remarkably, we correlated MMSE score and EEG source in all subjects as a single group, since the range of the MMSE score within the single groups was very low. Furthermore, this procedure is in line with the transition hypothesis about MCI condition.

The mentioned 3 lobar LORETA sources were then used as an input for the correlation with the indexes of the 


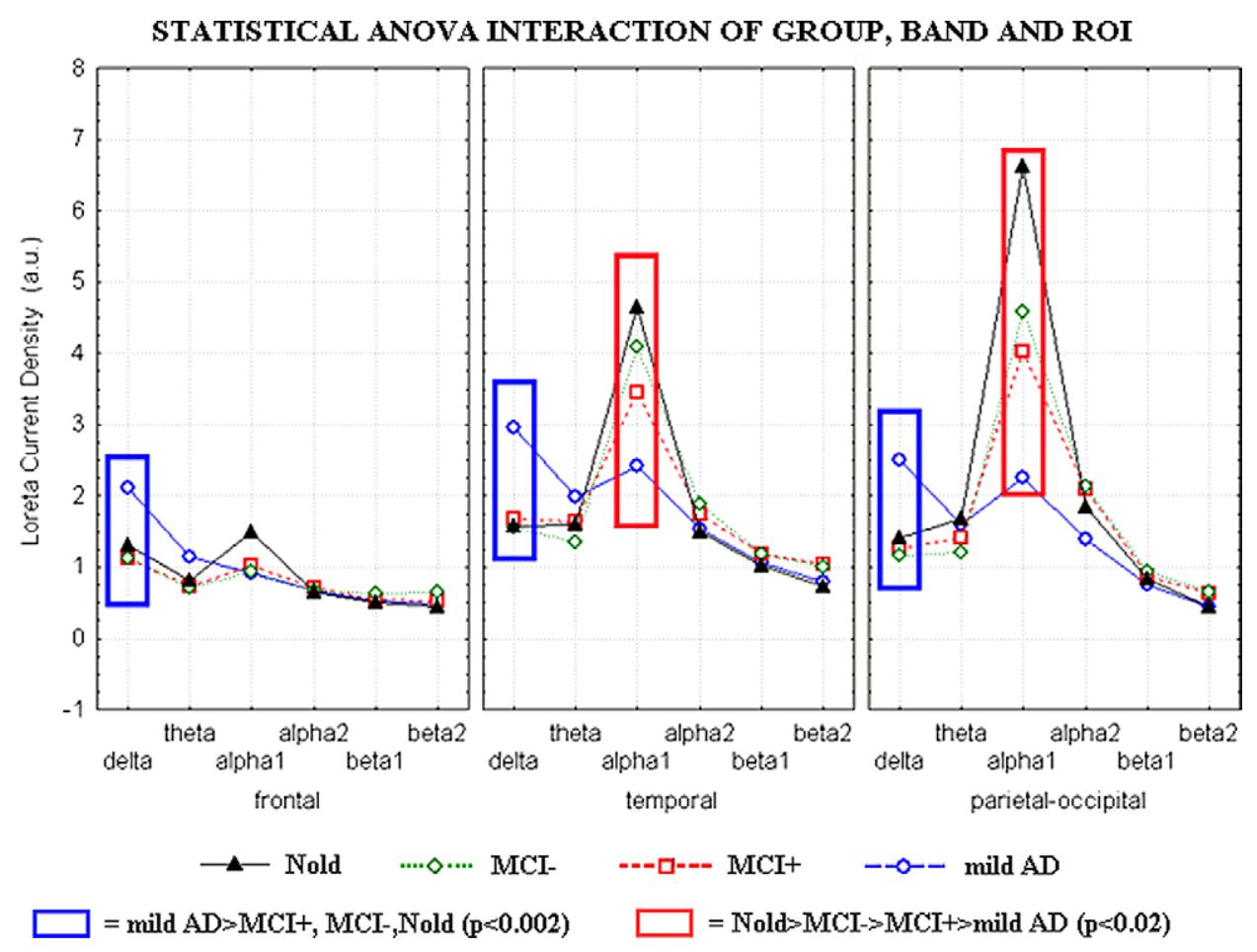

Fig. 3. Lobar LORETA solutions (mean across subjects) relative to a statistical ANOVA interaction among the factors Group (Nold, MCI-, MCI +, mild $\mathrm{AD}$ ), Band (delta, theta, alpha 1, alpha 2, beta 1, beta 2), and ROI (frontal, parietal-occipital, temporal). This ANOVA design used the normalized relative current density values at lobar level as a dependent variable. Subjects' age, education and individual alpha frequency peak (IAF) were used as covariates. Regional LORETA solutions modeled the EEG relative power spectra as revealed by a sort of 'virtual' intracranial macro-electrodes 'disposed' on the macrocortical regions of interest. Legend: the rectangles indicate the cortical regions and frequency bands in which LORETA solutions presented statistically significant LORETA patterns mild $\mathrm{AD} \neq$ Nold, MCI - , MCI $+(P<0.05$, planned Duncan post hoc testing $)$. A sub-group of the mentioned rectangles emphasize the following source sub-pattern Nold $>$ MCI $->$ MCI $+>$ mild AD. See Section 2 for further details.

corresponding lobar brain volumes in $\mathrm{MCI}$ and mild $\mathrm{AD}$ subjects as a whole group (Pearson test). In particular, (i) the amplitude of the frontal delta LORETA sources was correlated with frontal WM, GM, and CSF; (ii) the amplitude of the temporal delta LORETA sources was correlated with temporal WM, GM, and CSF; (iii) the amplitude of the parietal-occipital alpha 1 LORETA sources was correlated with parietal-occipital WM, GM, and CSF. The results showed a statistically significant negative correlation between frontal delta LORETA sources and frontal WM in the MCI and mild AD subjects $(r=-0.27$, $P=0.009$ ). Fig. 4 shows the scatterplot of that correlation. Of note, the correlation analysis of the frontal brain volume and frontal LORETA delta sources gave no statistically significant results when applied at the MCI and mild AD groups considered separately.

\subsection{Control statistical analyses}

As previously mentioned, a significant negative correlation was observed between frontal WM and amplitude of the frontal delta LORETA sources in MCI and mild AD subjects considered as a single group. However, one may argue that the results could be merely due to age effect. As a first control analysis, a partial correlation analysis (Pearson test $P<0.05)$ tested whether that correlation was not due to age differences between MCI and mild AD groups. The partial correlation analysis gave a statistically significant result $(P=0.04 ; r=-0.21)$ confirming the results of Section 2.

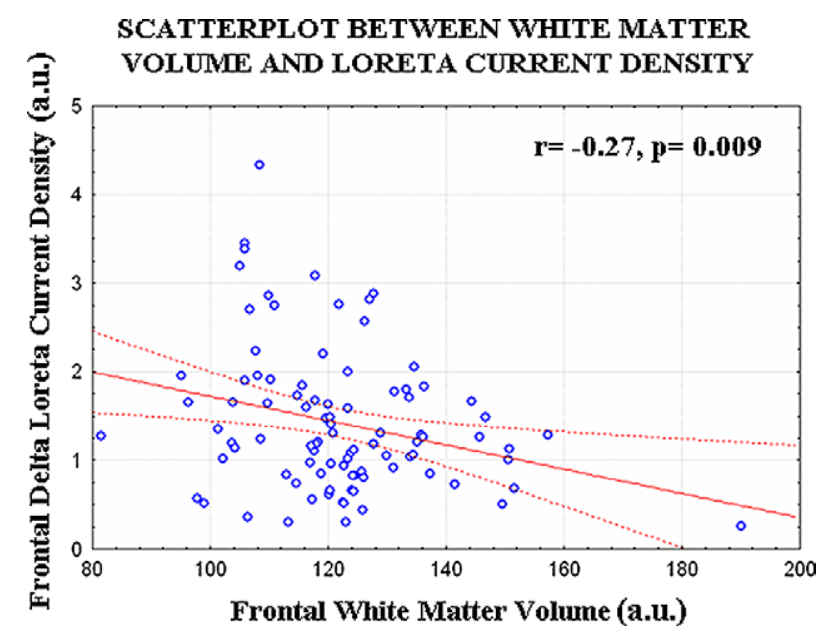

Fig. 4. Scatterplots among the frontal delta LORETA density current and frontal white matter (WM) volume in $\mathrm{MCI}-, \mathrm{MCI}+$, and mild $\mathrm{AD}$ subjects as a single group. The $r$ and $P$ values are reported within the diagram. 
As aforementioned, the statistical ANOVA and preliminary correlation analyses of lobar LORETA solutions and MMSE were performed on Nold, MCI-, MCI + and AD subjects, to select EEG sources sensitive to continuous processes across physiological and pathological aging. Diversely, the correlation between the selected EEG sources and corresponding lobar structural indexes was computed just on MCI and AD subjects. To verify whether the initial inclusion of Nold group could bias the results, a second control ANOVA analysis was performed. In this analysis, we considered only 3 groups of $30 \mathrm{MCI}-, 35 \mathrm{MCI}+$ and 28 mild AD subjects. The lobar LORETA solutions were used as a dependent variable. The ANOVA factors (levels) were Group (MCI-, MCI + , mild $\mathrm{AD}$; independent analysis), Band (delta, theta, alpha 1 , alpha 2 , beta 1 , beta 2 ), and ROI (frontal, parietal-occipital, temporal). There was a statistical interaction $(F(20,900)=3.4 ; \mathrm{MSe}=0.63$; $P=0.0001$ ) among factors Group, Band and ROI. The planned post hoc testing showed that the source pattern mild $\mathrm{AD} \neq \mathrm{MCI}-$, MCI + was fitted by the following 5 lobar LORETA solutions: parietal-occipital and temporal alpha 1 sources $(P<0.000004$ to $P<0.000001)$ as well as frontal, parietal-occipital, and temporal delta sources $(P<0.00001$ to $P<0.00002)$. This control ANOVA analysis fully confirmed the results obtained with the inclusion of Nold group. These 5 lobar LORETA solutions were correlated with the MMSE score in all subjects as a whole group (Spearman test; Bonferroni correction for 5 repetitions of the test gave the threshold $P<0.01$ to obtain the Bonferroni corrected $P<0.05)$. The MMSE score negatively correlated with the frontal $(r=-0.27, P=0.007)$ and temporal $(r=-0.26, P=0.01)$ delta sources. Therefore, the frontal delta and temporal delta LORETA sources were selected for the following correlation with corresponding lobar volumes either including either excluding the Nold group in the statistical analysis of the lobar LORETA solutions

A third control ANOVA analysis tested the hypothesis that the LORETA source differences among Nold, MCI- , $\mathrm{MCI}+$ and mild $\mathrm{AD}$ groups were not due to age, education, and gender. We considered sub-groups of Nold $(N=17)$, MCI $-(N=17), \mathrm{MCI}+(N=17)$ and mild $\mathrm{AD}(N=17)$ subjects, having practically equal age (from 73.4 to 73.5 years), education (from 8.1 to 8.4 years), and ratios of gender (10 female and 7 male). The lobar LORETA solutions were used as a dependent variable. The ANOVA factors (levels) were Group (Nold, MCI-, MCI+, mild $\mathrm{AD}$; independent analysis), Band (delta, theta, alpha 1, alpha 2, beta 1, beta 2), and ROI (frontal, parietal-occipital, temporal). There was a statistical interaction $(F(30,640)=$ 3.72; $\mathrm{MSe}=0.66 ; P=0.0001$ ) among factors Group, Band and ROI. The Duncan planned post hoc testing fully confirmed the results obtained with the larger groups. Therefore, the LORETA source differences obtained in the full groups were not due to age, education, and gender.

A fourth control ANOVA analysis was performed excluding 6 subjects with MMSE $<24$ in MCI+ group, although MMSE does not provide a cut-off for AD diagnosis and MCI status was accurately assessed by specialized clinicians (see Section 2). Therefore, we considered groups of 34 Nold, $24 \mathrm{MCI}-, 35 \mathrm{MCI}+$ and 28 mild AD subjects. The lobar LORETA solutions were used as a dependent variable. The ANOVA factors (levels) were Group (Nold, $\mathrm{MCI}-, \mathrm{MCI}+$, mild $\mathrm{AD}$; independent analysis), Band (delta, theta, alpha 1, alpha 2, beta 1 , beta 2), and ROI (frontal, parietal-occipital, temporal). There was a statistical interaction $(F(30,1170)=4.15 ; \mathrm{MSe}=0.81 ; P=0.0001)$ among factors Group, Band and ROI. According to the statistical results obtained in the full groups, the Duncan planned post hoc testing showed that the source pattern mild $\mathrm{AD} \neq$ Nold, MCI - , MCI + was fitted by the following 5 lobar LORETA solutions: parietal-occipital and temporal alpha 1 sources $(P<0.000005$ to $P<0.000001)$ as well as frontal, parietal-occipital, and temporal delta sources $(P<0.003$ to $P<0.000002)$. This control ANOVA analysis fully confirmed the results obtained with the full MCI+ group. Therefore, the LORETA source differences obtained in the full groups were not due to the MCI + subjects with MMSE $<24$.

A fifth control ANOVA analysis tested the hypothesis that the LORETA source differences among Nold, MCI-, $\mathrm{MCI}+$ and mild $\mathrm{AD}$ groups were not due to differences in the IAF. In this control ANOVA analysis, we considered 3 EEG sub-bands, whose band limits were defined according to the IAF (Klimesch, 1996; 1999; Klimesch et al., 1998). The frequencies of the 3 sub-bands were: (i) from IAF- $4 \mathrm{~Hz}$ to IAF-2 $\mathrm{Hz}$, (ii) from IAF-2 $\mathrm{Hz}$ to IAF, and (iii) from IAF to IAF $+2 \mathrm{~Hz}$. The lobar LORETA solutions at these 3 subbands were used as a dependent variable. The ANOVA factors were Group (Nod, MCI - , MCI +, mild AD), SubBand (IAF-4 to IAF-2, IAF-2 to IAF, IAF to IAF + 2), and ROI (frontal, parietal-occipital, temporal). Subjects' age and education were used as covariates. There was a statistical interaction $(F(12,492)=2.7 ; \quad \mathrm{MSe}=1.34$; $P<0.0016)$ among the factors Group, Sub-Band, and ROI. The Duncan planned post hoc testing showed that the source pattern mild $\mathrm{AD} \neq$ Nold, $\mathrm{MCI}-$, MCI + was fitted by the sub-band from IAF-2 to IAF (parietal-occipital and temporal areas, $P<0.0002$ to $P<0.000001)$ and by the sub-band from IAF $\mathrm{Hz}$ to IAF $+2 \mathrm{~Hz} \mathrm{IAF} \mathrm{(parietal-occipital}$ and temporal areas, $P<0.0001$ to $P<0.000001$ ). Furthermore, in the sub-band from IAF to IAF +2 , the parietaloccipital sources showed stronger amplitude in Nold compared to $\mathrm{MCI}-$ group $(P<0.001)$ and in $\mathrm{MCI}-$ compared to MCI + group $(P<0.05)$, while the temporal sources showed stronger amplitude in Nold compared to MCI - and MCI $+(P<0.001)$. On the whole, these ANOVA results fully confirmed those obtained with the fixed EEG bands.

Finally, a sixth control ANOVA analysis was carried out to verify that the low-band delta $(0.5-1.5 \mathrm{~Hz})$ as revealed by the LORETA solutions had amplitude sensitive to the cognitive status of Nold, $\mathrm{MCI}-, \mathrm{MCI}+$, and mild $\mathrm{AD}$ 
subjects. To this aim, the low-band delta LORETA solutions from Nold, MCI - , MCI + and mild AD subjects were used as an input for an ANOVA analysis, which used subjects' age, education, and IAF peak as covariates. The ANOVA analysis also used the factors Group (Nold, MCI-, MCI+, mild AD; independent analysis) and ROI (frontal, parietaloccipital, temporal). There was only a main statistical effect for $\operatorname{Group}(F(3,120)=4.2 ; \mathrm{MSe}=83.9 ; P<0.007)$. Duncan post hoc testing indicated that the LORETA sources at lowband delta had stronger amplitude in AD group compared to Nold $(P<0.01)$, MCI $-(P<0.001)$ and MCI $+(P<0.003)$ groups. Remarkably, we preferred to exclude the low-band delta LORETA solutions in the ANOVA analysis including the other 6 bands (delta, theta, alpha 1, alpha 2, beta 1, and beta 2) for two reasons: (i) the low-band delta could be affected by residual ocular and instrumental artifacts; (ii) the inclusion of low-band delta would have increase the number of level of factor band. The frontal, parietal-occipital and temporal low-band delta LORETA solutions were correlated with the MMSE score in all subjects as a whole group (Spearman test). There was no statistically significant correlations $(P>0.05)$. Therefore, the low-band delta LORETA sources were no specifically sensitive to pathological aging across the recruited Nold, MCI, and mild AD subjects.

\section{Discussion}

\subsection{Sources of delta and alpha rhythms change across Nold, $M C I$ and $A D$ subjects}

A preliminary control analysis allowed the modeling of resting EEG sources (LORETA solutions) sensitive to global cognitive status (MMSE score) in the recruited Nold, MCI, and mild AD subjects. When compared to Nold subjects, EEG rhythms in MCI and mild AD subjects were characterized by a marked magnitude decrease of alpha 1 sources in parieto-occipital and temporal areas. In mild AD subjects, they were also characterized by a marked magnitude increase of frontal, parieto-occipital, and temporal delta sources. Across all Nold, MCI, and mild AD subjects, MMSE score (global cognitive level) was correlated with the amplitude of alpha 1 sources in parietooccipital areas and with the amplitude of delta sources in frontal and temporal areas. Finally, slow component of the delta rhythms $(0.5-1.5 \mathrm{~Hz})$ pointed to sources higher in amplitude in mild AD than the other groups. However, they showed no statistically significant correlation with MMSE score $(P>0.01)$. These results are globally in line with previous evidence showing an enhancement of the delta rhythms in AD compared to Nold subjects (Babiloni et al., 2004a, 2005b,c; Koenig et al., 2005; Prichep et al., 1994; Wolf et al., 2003) and a magnitude decrease of the alpha rhythms in AD and/or MCI compared to Nold subjects (Babiloni et al., 2004a, 2005b,c; Dierks et al., 1993; 2000;
Koenig et al., 2005; Moretti et al., 2004; Rodriguez et al., 1999a,b). From a methodological viewpoint, they validated the present procedures for subjects' selection and EEG data analysis, thus corroborating the novel results of the present study (i.e. the relationships among lobar brain volume and corresponding EEG sources).

The aforementioned results arise the issue of cerebral systems that produce and modulate delta and alpha rhythms in normal conditions. In the condition of slow-wave sleep, corticofugal slow oscillations $(<1 \mathrm{~Hz})$ are effective in grouping thalamic-generated delta rhythms $(1-4 \mathrm{~Hz})$ and spindling activity $(7-14 \mathrm{~Hz})$ rhythms (Steriade, 2003). In the condition of brain arousal, spindles, high and low components of the delta rhythms are blocked by the inhibition of oscillators within, respectively, reticulothalamic $(7-14 \mathrm{~Hz})$, thalamo-cortical $(1-4 \mathrm{~Hz})$, and intracortical $(<1 \mathrm{~Hz})$, neuronal circuits. These rhythms are replaced by fast (beta and gamma) cortical oscillations, which are mainly induced by forebrain (nucleus basalis) cholinergic inputs to hippocampus and cortex as well as by thalamocortical projections (Steriade, 2003; Steriade et al., 1996). In the condition of awake rest, low-band $(8-10.5 \mathrm{~Hz})$ alpha would be mainly related to subject's global attentional readiness (Klimesch, 1996; Klimesch et al., 1997; 1998; Rossini et al., 1991; Steriade and Llinas, 1988) and would mainly reflect time-varying inputs of forebrain cholinergic pathways (Ricceri et al., 2004). However, it should be noted that brain arousal and corresponding EEG oscillations are commonly considered as due to not only cholinergic systems. Rather, they would depend on a complex balance among cholinergic, serotoninergic, histaminergic, noradrenergic, glutammaergic, and GABAergic neurotransmitters systems.

Keeping this theoretical framework in mind, changes of resting delta and alpha rhythms in MCI and mild $\mathrm{AD}$ subjects might be mainly due to the impairment of nucleusbasalis cholinergic neurons. This impairment would uninhibit cortical slow oscillators triggering delta and spindles' pacemakers at thalamic level (Steriade, 2003). Furthermore, it would reduce cortico-cortical functional coupling of EEG rhythms, that is the main generation mechanism of awake resting alpha rhythms at parietooccipital cortex (Manshanden et al., 2002; Nunez et al., 2001). Together with cholinergic systems, monoamminergic (Dringenberg, 2000) and non-NMDA vs. NMDS glutammaergic unbalance (Di Lazzaro et al., 2004) might affect cortical excitability and EEG rhythms in AD.

\subsection{Frontal brain volume and delta EEG sources negatively correlated in MCI and mild $A D$ subjects}

As a main result of the present study, a negative correlation was observed between frontal WM and amplitude of the frontal delta sources (as revealed by LORETA solutions) in MCI and AD subjects considered as a single group. A crucial question is then why did lobar 
brain volume affect delta but not alpha rhythms in MCI and AD subjects? Keeping in mind the mentioned theoretical framework, it can be speculated that this would depend on the loss of cholinergic basal forebrain neurons projecting to hippocampus and fronto-parietal connections (Helkala et al., 1996; Holschneider et al., 1999; Mesulam et al., 2004). These neurons would be the main responsible together with serotoninergic neurons of the replacement of spindles and delta rhythms by fast EEG rhythms during wakefulness (Dringenberg, 2000; Dringenberg et al., 2002). The loss of cholinergic basal forebrain neurons projecting to hippocampus and frontal areas might explain at least in part the present results. Several lines of evidence have shown that experimental lesions of the basal forebrain increased the amplitude of slow EEG rhythms and decreased that of faster EEG rhythms, respectively (Buzsaki et al., 1988; Ray and Jackson, 1991; Stewart et al., 1984). The same was true for slow EEG rhythms in AD subjects supposed to have an impairment of cholinergic basal forebrain (Babiloni et al., 2004a; Dierks et al., 1993; 2000; Huang et al., 2000; Mesulam et al., 2004; Moretti et al., 2004; Rodriguez et al., 1999a,b).

These lesions were found to relatively spare brainstem cholinergic innervation of the thalamus (Geula and Mesulam, 1989; 1996; 1999; Mash et al., 1985; Mesulam et al., 2004). Finally, cholinergic basal forebrain was more structurally impaired in AD responders than non-responders to cholinergic therapy (Tanaka et al., 2003).

The above 'cholinergic' explanation fits with the mentioned previous evidence. However, at lest two issues should be taken into account. Firstly, the relationships between cholinergic tone and neurodegenerative processes in $\mathrm{AD}$ may be non-linear. Indeed, two studies have suggested that cognitive deficits in MCI and early AD were not associated with the loss of cholinergic levels (Davis et al., 1999; DeKosky et al., 2002). In the first study (Davis et al., 1999), neocortical cholinergic deficits were characteristic of severely demented AD patients, but cholinergic deficits were not apparent in individuals with mild AD. In the second study (DeKosky et al., 2002), the cholinergic system determined compensatory responses during the early stage of dementia (DeKosky et al., 2002). This up-regulation was seen in frontal cortex and could be an important factor in preventing the transition of MCI subjects to AD (DeKosky et al., 2002). Finally, it should be remarked that abnormal EEG rhythms can be observed not only in people with pathological aging but also in other kinds of neurologic disorders not clearly related to an impairment of cholinergic systems (Priori et al., 2004). Secondly, according to the above 'cholinergic' explanation, the impairment of cholinergic inputs to cortex should impinge upon correlations between frontal WM and alpha rhythms and between frontal WM and delta rhythms. This was not the case. A reasonable explanation is that the alpha rhythms of MCI and $\mathrm{AD}$ subjects were sensitive to functional abnormalities of cortical neurons impinged by cholinergic neurons rather than to their structural deficit

This explanation is in line with previous findings in AD patients showing a clearcut correlation of delta rhythms with neuronal death in mesial-temporal and posterior cortical areas (Fernandez et al., 2003). Furthermore, there is a bulk of previous findings on the strict relationship between cerebral atrophy or lesion and generation of delta rhythms (de Jongh et al., 2003; Harmony et al., 1993; Hensel et al., 2004; Murri et al., 1998).

Another question raised by the present results is why the correlation of the frontal delta source is specifically with WM. A tentative explanation relies on the loss of neuronal fibers of basal forebrain cholinergic neurons projecting to frontal lobe and of frontal cortical neurons impinged by them (Helkala et al., 1996; Holschneider et al., 1999; Mesulam et al., 2004). Volume reduction of the WM would reflect the impairment of input/output cortical information flows to frontal lobe in MCI and AD subjects. This would cause a frontal 'disconnection mode' that would pathologically disclose the cortico-fugal EEG rhythms triggering thalamus-cortical delta rhythms. This explanation emphasizes the possibility that abnormal connectivity to and from frontal lobe impinges more effectively upon the generation of the local delta rhythms than the volume of the frontal GM does. The explanation is in line with the idea that EEG rhythms strongly depend on mechanisms that spread the neural synchronization/desynchronization to recruit or inhibit cortical modules. It is also in line with recent evidence showing that in mild to moderate AD patients, WM hyper-intensity involved frontal lobes and was significantly correlated with memory, verbal fluency, and executive performance (Capizzano et al., 2004; Gootjes et al., 2004; Tullberg et al., 2004). There are strict relationships among that structural impairment of frontal lobe, increase of slow EEG rhythms, and relative cortical hypoperfusion of blood (Brenner et al., 1986; Dossi et al., 1992; Kwa et al., 1993; Nobili et al., 1998; Passero et al., 1995; Rae-Grant et al., 1987; Rodriguez et al., 1999a; Steriade, 1994; Stigsby et al., 1981).

A last question raised by the present results is why did lobar brain volume affect frontal delta but not temporal delta activity in MCI and AD subjects? Indeed, previous studies have shown an effect of early mesial-temporal degeneration on hippocampus-temporoparietal connectivity in MCI and AD subjects (Killiany et al., 1993) and an effect of hippocampal-entorhinal atrophy on posterior delta rhythms in AD subjects (Fernandez et al., 2003). In the present study, the absence of relationship between lobar brain volume and temporal activity is probably due to the fact that we used a conventional but low EEG spatial sampling (19 channels) and a compatible EEG source analysis having a low spatial resolution (LORETA). Such methodological limitations did not allow the evaluation of the correlations among fine structural features of mesial-temporal cortex and posterior EEG slow rhythms. 


\section{Conclusions}

We have confirmed for the first time the hypothesis that sources of the resting EEG rhythms are correlated with spatially corresponding lobar brain volume across MCI and $\mathrm{AD}$ subjects. We found a negative correlation between the frontal delta sources with global cognitive status (MMSE) and the volume of frontal WM. The present findings further support the 'transition hypothesis' of brain structural and functional continuity between $\mathrm{MCI}$ and mild $\mathrm{AD}$, at least at group level. They also prompt future studies for the identification of MCI individuals with extremely high statistical chances of progressing to $\mathrm{AD}$, based on combined structural and functional indexes of the brain. To that aim, future studies might integrate the present approach with the evaluation of the relationships between cortical rhythms and temporo-mesial atrophy. This would also provide an independent validation of recent magnetoencephalographic evidence showing strict relationships among parietotemporal delta sources and atrophy of hippocampus in $\mathrm{AD}$ patients (Fernandez et al., 2003).

\section{Acknowledgements}

We thank Dr/Prof. Lanuzza Bartolo, Francesca Bergami, Leonardo Frigerio, Massimo Gennarelli, Nicola Girtler, and Katiuscia Sosta for their precious help in the development of the present study. We thank also Prof. Fabrizio Eusebi for his continuous support. The reaserch was grated by Association Fatebenefratelli for Research (AFaR)

\section{References}

Achermann P, Borbely AA. Low-frequency $(<1 \mathrm{~Hz})$ oscillations in the human sleep electroencephalogram. Neuroscience 1997;81(1):213-22.

Albert M, Smith LA, Scherr PA, Taylor JO, Evans DA, Funkenstein HH. Use of brief cognitive tests to identify individuals in the community with clinically diagnosed Alzheimer's disease. Int J Neurosci 1991; 57(3-4):167-78

Amzica F, Steriade M. The K-complex: its slow $(<1-\mathrm{Hz})$ rhythmicity and relation to delta waves. Neurology 1997;49(4):952-9.

Anderer P, Pascual-Marqui RD, Semlitsch HV, Saletu B. Differential effects of normal aging on sources of standard N1, target N1 and target P300 auditory event-related brain potentials revealed by low resolution electromagnetic tomography (LORETA). Electroencephalogr Clin Neurophysiol 1998a;108(2):160-74.

Anderer P, Saletu B, Semlitsch HV, Pascual-Marqui RD. Electrical sources of P300 event-related brain potentials revealed by low resolution electromagnetic tomography. 2. Effects of nootropic therapy in ageassociated memory impairment. Neuropsychobiology 1998b;37(1): $28-35$.

Anderer P, Saletu B, Pascual-Marqui RD. Effect of the 5-HT(1A) partial agonist buspirone on regional brain electrical activity in man: a functional neuroimaging study using low-resolution electromagnetic tomography (LORETA). Psychiatry Res 2000;100(2):81-96.

Anderer P, Saletu B, Semlitsch HV, Pascual-Marqui RD. Non-invasive localization of P300 sources in normal aging and age-associated memory impairment. Neurobiol Aging 2003;24(3):463-79.
Anderer P, Saletu B, Saletu-Zyhlarz G, Gruber D, Metka M, Huber J, Pascual-Marqui RD. Brain regions activated during an auditory discrimination task in insomniac postmenopausal patients before and after hormone replacement therapy: low-resolution brain electromagnetic tomography applied to event-related potentials. Neuropsychobiology 2004;49(3):134-53.

Arnaiz E, Almkvist O. Neuropsychological features of mild cognitive impairment and preclinical Alzheimer's disease. Acta Neurol Scand 2003;107:34-41.

Babiloni C, Binetti G, Cassetta E, Cerboneschi D, Dal Forno G, Del Percio C, Ferreri F, Ferri R, Lanuzza B, Miniussi C, Moretti DV, Nobili F, Pascual-Marqui RD, Rodriguez G, Romani GL, Salinari S, Tecchio F, Vitali P, Zanetti O, Zappasodi F, Rossini PM. Mapping distributed sources of cortical rhythms in mild Alzheimer's disease. A multi-centric EEG study. Neuroimage 2004a;22(1):57-67.

Babiloni C, Ferri R, Moretti DV, Strambi A, Binetti G, Dal Forno G, Ferreri F, Lanuzza B, Bonato C, Nobili F, Rodriguez G, Salinari S, Passero S, Rocchi R, Stam CJ, Rossini PM. Abnormal fronto-parietal coupling of brain rhythms in mild Alzheimer's disease: a multicentric EEG study. Eur J Neurosci 2004b;19(9):2583-90.

Babiloni C, Babiloni F, Carducci F, Cincotti F, Del Percio C, Della Penna S, Franciotti R, Pignotti S, Pizzella V, Rossini PM, Sabatini E, Torquati K, Romani GL. Human alpha rhythms during visual delayed choice reaction time tasks. A MEG study. Hum Brain Mapp 2004c;24(3): 184-92.

Babiloni C, Babiloni F, Carducci F, Cappa S, Cincotti F, Del Percio C, Miniussi C, Moretti DV, Rossi S, Sosta K, Rossini PM. Human cortical rhythms during visual delayed choice reaction time tasks. A highresolution EEG study on normal aging. Behav Brain Res 2004d;153(1): 261-71.

Babiloni C, Miniussi C, Babiloni F, Carducci F, Cincotti F, Del Percio C, Sirello G, Sosta K, Nobre AC, Paolo M, Rossini PM. Sub-second 'temporal attention' modulates alpha rhythms. A high-resolution EEG study. Cogn Brain Res 2004e;19(3):259-68.

Babiloni C, Babiloni F, Carducci F, Cappa S, Cincotti F, Del Percio C, Miniussi C, Moretti DV, Rossi S, Sosta K, Rossini PM. Human cortical responses during one-bit short-term memory. A high-resolution EEG study on delayed choice reaction time tasks. Clin Neurophysiol 2004f; 115(1):161-70.

Babiloni C, Babiloni F, Carducci F, Cappa S, Cincotti F, Del Percio C, Miniassi C, Moretti DV, Pasqualetti P, Rossi S, Sosta K, Rossini PM. Human cortical EEG rhythms during long-term episodic memory task. A high resolution EEG study of the HERA model. Neuroimage 2004g; 21(4):1576-84.

Babiloni C, Binetti G, Cassarino A, Dal Forno G, Del Percio C, Ferreri F, Ferri R, Frisoni G, Galderisi S, Hirata K, Lanuzza B, Miniussi C, Mucci A, Nobili F, Rodriguez G, Romani GL, Rossini PM. Sources of cortical rhythms in adults during physiological aging: a multi-centric EEG study. Hum Brain Mapp 2005a; [Epub ahead of print].

Babiloni C, Cassetta E, Chiovenda P, Del Percio C, Ercolani M, Moretti DV, Moffa F, Pasqualetti P, Pizzella V, Romani GL, Tecchio F, Zappasodi F, Rossini PM. Frontomedial alpha hyperreactivity in mild demented patients during visual delayed response tasks. A MEG study. Brain Res Bull 2005b;65(6):457-70.

Babiloni C, Binetti G, Cassetta E, Dal Forno G, Del Percio C, Ferreri F, Ferri R, Frisoni G, Hirata K, Lanuzza B, Miniussi C, Moretti DV, Nobili F, Rodriguez G, Romani GL, Salinari S, Rossini PM. Sources of cortical rhythms change as a function of cognitive impairment in pathological aging: a multi-centric study. Clin Neurophysiol 2006a;117(2):252-68.

Babiloni C, Benussi L, Binetti G, Cassetta E, Dal Forno G, Del Percio C, Ferreri F, Ferri R, Frisoni G, Ghidoni R, Miniussi C, Rodriguez G, Romani GL, Squitti R, Ventriglia MC, Rossini PM. Apolipoprotein E and alpha brain rhythms in mild cognitive impairment: a multicentric EEG study. Ann Neurol 2006b;59(2):323-34.

Bachman DL, Wolf PA, Linn RT, Knoefel JE, Cobb JL, Belanger AJ, White LR, D'Agostino RB. Incidence of dementia and probable 
Alzheimer's disease in a general population. The Framingham Study. Neurology 1993;43:515-9.

Baron JC, Chételat G, Desgranges B, Perchey G, Landeau B, de la Sayette V, Eustache F. In vivo mapping of grey matter loss with voxelbased morphometry in mild Alzheimer's disease. Neuroimage 2001;14: 298-309.

Bartzokis G, Beckson M, Lu PH, Nuechterlein KH, Edwards N, Mintz J. Age-related changes in frontal and temporal lobe volumes in men: a magnetic resonance imaging study. Arch Gen Psychiatry 2001;58(5): 461-5.

Bennett DA, Wilson RS, Schneider JA, Evans DA, Beckett LA, Aggarwal NT, Barnes LL, Fox JH, Bach J. Natural history of mild cognitive impairment in older persons. Neurology 2002;59(2):198-205.

Besthorn C, Zerfass R, Geiger-Kabisch C, Sattel H, Daniel S, SchreiterGasser U, Forstl H. Discrimination of Alzheimer's disease and normal aging by EEG data. Electroencephalogr Clin Neurophysiol 1997; 103(2):241-8.

Braak H, Braak E. Neuropathological stageing of Alzheimer-related changes. Acta neuropathol 1991;82:239-59.

Brenner RP, Ulrich RF, Spiker DG, Sclabassi RJ, Reynolds III CF, Marin RS, Boller F. Computerized EEG spectral analysis in elderly normal, demented and depressed subjects. Electroencephalogr Clin Neurophysiol 1986;64:483-92.

Buchan RJ, Nagata K, Yokoyama E, Langman P, Yuya H, Hirata Y, Hatazawa J, Kanno I. Regional correlations between the EEG and oxygen metabolism in dementia of Alzheimer's type. Electroencephalogr Clin Neurophysiol 1997;103(3):409-17.

Buzsaki G, Bickford RG, Ponomareff G, Thal LJ, Mandel R, Gage FH. Nucleus basalis and thalamic control of neocortical activity in the freely moving rat. J Neurosci 1988;8(11):4007-26.

Capizzano AA, Acion L, Bekinschtein T, Furman M, Gomila H, Martinez A, Mizrahi R, Starkstein SE. White matter hyperintensities are significantly associated with cortical atrophy in Alzheimer's disease. J Neurol Neurosurg Psychiatry 2004;75(6):822-7.

Celsis P, Agniel A, Puel M, Le Tinnier A, Viallard G, Demonet JF, Rascol A, Marc-Vergnes JP. Lateral asymmetries in primary degenerative dementia of the Alzheimer type, a correlative study of cognitive, haemodynamic and EEG data, in relation with severity, age of onset and sex. Cortex 1990;26(4):585-96.

Chetelat G, Desgranges B, de la Sayette V, Viader F, Eustache F, Baron JC. Mapping gray matter loss with voxel-based morphometry in mild cognitive impairment. NeuroReport 2002;13:1939-43.

Chiaramonti R, Muscas GC, Paganini M, Muller TJ, Fallgatter AJ, Versari A, Strik WK. Correlations of topographical EEG features with clinical severity in mild and moderate dementia of Alzheimer type. Neuropsychobiology 1997;36(3):153-8.

Cincotti F, Babiloni C, Miniussi C, Carducci F, Moretti D, Salinari S, Pascual-Marqui R, Rossini PM, Babiloni F. EEG deblurring techniques in a clinical context. Methods Inf Med 2004;43(1):114-7.

Cook IA, Leuchter AF. Synaptic dysfunction in Alzheimer's disease: clinical assessment using quantitative EEG. Behav Brain Res 1996; 78(1):15-23.

Davis KL, Mohs RC, Marin D, Purohit DP, Perl DP, Lantz M, Austin G, Haroutunian V. Cholinergic markers in elderly patients with early signs of Alzheimer disease. J Am Med Assoc 1999;281(15):1401-6.

de Jongh A, Baayen JC, de Munck JC, Heethaar RM, Vandertop WP, Stam CJ. The influence of brain tumor treatment on pathological delta activity in MEG. Neuroimage 2003;20(4):2291-301.

de Leon MJ, DeSanti S, Zinkowski R, Mehta PD, Pratico D, Segal S, Clark C, Kerkman D, DeBernardis J, Li J, Lair L, Reisberg B, Tsui W, Rusinek H. MRI and CSF studies in the early diagnosis of Alzheimer's disease. J Intern Med 2004;256(3):205-23.

DeCarli C, Maisog J, Murphy DG, Teichberg D, Rapoport SI, Horwitz B. Method for quantification of brain, ventricular, and subarachnoid CSF volumes from MR images. J Comput Assist Tomogr 1992;16(2): $274-84$.
DeCarli C, Murphy DG, Gillette JA, Haxby JV, Teichberg D, Schapiro MB, Horwitz B. Lack of age-related differences in temporal lobe volume of very healthy adults. AJNR Am J Neuroradiol 1994;15(4):689-96.

DeKosky ST, Ikonomovic MD, Styren SD, Beckett L, Wisniewski S, Bennett DA, Cochran EJ, Kordower JH, Mufson EJ. Upregulation of choline acetyltransferase activity in hippocampus and frontal cortex of elderly subjects with mild cognitive impairment. Ann Neurol 2002; 51(2): 145-55.

Devanand DP, Folz M, Gorlyn M, Moeller JR, Stern J. Questionable dementia: clinical course and predictors of outcome. J Am Geriatr Soc 1997;45:321-8.

Dierks T, Ihl R, Frolich L, Maurer K. Dementia of the Alzheimer type: effects on the spontaneous EEG described by dipole sources. Psychiatry Res 1993;50(3):151-62.

Dierks T, Jelic V, Pascual-Marqui RD, Wahlund LO, Julin P, Linden DEJ, Maurer K, Winblad B, Nordberg A. Spatial pattern of cerebral glucose metabolism (PET) correlates with localization of intracerebral EEGgenerators in Alzheimer's disease. Clin Neurophysiol 2000;111: $1817-24$.

Di Lazzaro V, Oliviero A, Pilato F, Saturno E, Dileone M, Marra C, Daniele A, Ghirlanda S, Gainotti G, Tonali PA. Motor cortex hyperexcitability to transcranial magnetic stimulation in Alzheimer's disease. J Neurol Neurosurg Psychiatry 2004;75:555-9.

Dossi RC, Nunez A, Steriade M. Electrophysiology of a slow $(0.5-4 \mathrm{~Hz})$ intrinsic oscillation of cat thalamocortical neurones in vivo. J Physiol 1992;447:215-34.

Dringenberg HC. Alzheimer's disease: more than a 'cholinergic disorder'-evidence that cholinergic-monoaminergic interactions contribute to EEG slowing and dementia. Behav Brain Res 2000;115: 235-49.

Dringenberg HC, Rubenstein ML, Solty H, Tomaszek S, Bruce A. Electroencephalographic activation by tacrine, deprenyl, and quipazine: cholinergic vs. non-cholinergic contributions. Eur J Pharmacol 2002; 447(1):43-50.

Elmstahl S, Rosen I. Postural hypotension and EEG variables predict cognitive decline: results from a 5-year follow-up of healthy elderly women. Dement Geriatr Cogn Disord 1997;8(3):180-7.

Fernandez A, Arrazola J, Maestu F, Amo C, Gil-Gregorio P, Wienbruch C, Ortiz T. Correlations of hippocampal atrophy and focal low-frequency magnetic activity in Alzheimer disease: volumetric MR imagingmagnetoencephalographic study. AJNR Am J Neuroradiol 2003;24(3): 481-7.

Fisk JD, Merry HR, Rockwood K. Variations in case definition affect prevalence but not outcomes of mild cognitive impairment. Neurology 2003;61:1179-84.

Flicker CS, Ferris H, Reisberg B. Mild cognitive impairment in the elderly: predictors of dementia. Neurology 1991;41:1006-9.

Folstein MF, Folstein SE, McHugh PR. 'Mini mental state': a practical method for grading the cognitive state of patients for clinician. J Psychiatr Res 1975;12:189-98.

Frisoni GB, Beltramello A, Binetti G, Bianchetti A, Weiss C, Scuratti A, Trabucchi M. Related articles, computed tomography in the detection of the vascular component in dementia. Gerontology 1995;41(2): $121-8$.

Frisoni GB, Testa C, Zorzan A, Sabattoli F, Beltramello A, Soininen H, Laakso MP. Detection of gray matter loss in mild Alzheimer's disease with voxel-based morphometry. J Neurol Neurosurg Psychiatry 2002; 73:657-64

Frisoni GB, Padovani A, Wahlund LO. Alzheimer Dis Assoc Disord 2004; 18(2):51-3 [Alzheimer Dis Assoc Disord 2004;18(2):51-3].

Galluzzi S, Cimaschi L, Ferrucci L, Frisoni GB. Mild cognitive impairment: clinical features and review of screening instruments. Aging 2001;13(3):183-202.

Galluzzi S, Sheu CF, Zanetti O, Frisoni GB. Distinctive clinical features of mild cognitive impairment with subcortical cerebrovascular disease. Dement Geriatr Cogn Disord 2005;19(4):196-203. 
Gao S, Hendrie HC, Hall KS, Hui SL. The relationships between age, sex, and the incidence of dementia and Alzheimer's disease. A metaanalysis. Arch Gen Psychiatry 1998;55:809-15.

Geula C, Mesulam MM. Cortical cholinerigc fibers in aging and Alzheimer's disease: a morphometirc study. Neuroscience 1989;33: 469-81.

Geula C, Mesulam MM. Systematic regional variations in the loss of cortical cholinergic fibers in Alzheimer's disease. Cereb Cortex 1996;6: $165-77$.

Geula C, Mesulam MM. Cholinergic system in Alzheimer's disease. In: Terry RD, editor. Alzheimer disease. 2nd ed. Philadelphia, PA/Baltimore, MD: Lippincot/Williams and Wilkins; 1999. p. 69-292.

Goforth HW, Konopka L, Primeau M, Ruth A, O’Donnell K, Patel R, Poprawski T, Shirazi P, Rao M. Quantitative electroencephalography in frontotemporal dementia with methylphenidate response: a case study. Clin EEG Neurosci 2004;35(2):108-11.

Good CD, Johnsrude IS, Ashburner J, Henson RN, Friston KJ, Frackowiak RS. A voxel-based morphometric study of ageing in 465 normal adult human brains. Neuroimage 2001;14(1 Pt. 1):21-36.

Gootjes L, Teipel SJ, Zebuhr Y, Schwarz R, Leinsinger G, Scheltens P, Moller HJ, Hampel H. Regional distribution of white matter hyperintensities in vascular dementia, Alzheimer's disease and healthy aging. Dement Geriatr Cogn Disord 2004;18(2):180-8.

Harmony T, Fernandez-Bouzas A, Marosi E, Fernandez T, Bernal J, Rodriguez M, Reyes A, Silva J, Alonso M, Casian G. Correlation between computed tomography and voltage and current source density spectral EEG parameters in patients with brain lesions. Electroencephalogr Clin Neurophysiol 1993;87(4):196-205.

Helkala EL, Hanninen T, Hallikainen M, Kononen M, Laakso MP, Hartikainen P, Soininen H, Partanen J, Partanen K, Vainio P, Riekkinen Sr P. Slow-wave activity in the spectral analysis of the electroencephalogram and volumes of hippocampus in subgroups of Alzheimer's disease patients. Behav Neurosci 1996;110(6):1235-43.

Hensel S, Rockstroh B, Berg P, Elbert T, Schonle PW. Left-hemispheric abnormal EEG activity in relation to impairment and recovery in aphasic patients. Psychophysiology 2004;41(3):394-400.

Hernández JL, Valdés P, Biscay R, Virués T, Szava S, Bosch J, Riquenes A, Clark I. A global scale factor in brain topography. Int J Neurosci 1994; 76:267-78.

Holschneider DP, Waite JJ, Leuchter AF, Walton NY, Scremin OU. Changes in electrocortical power and coherence in response to the selective cholinergic immunotoxin 192 IgG-saporin. Exp Brain Res 1999;126(2):270-80.

Huang C, Wahlund LO, Dierks T, Julin P, Winblad B, Jelic V. Discrimination of Alzheimer's disease and mild cognitive impairment by equivalent EEG sources: a cross-sectional and longitudinal study. Clin Neurophysiol 2000;11:1961-7.

Huang C, Wahlund LO, Svensson L, Winblad B, Julin P. Cingulate cortex hypoperfusion predicts Alzheimer's disease in mild cognitive impairment. BMC Neurol 2002;2(1):9.

Hughes CP, Berg L, Danziger WL, Cohen LA, Martin RL. A new clinical rating scale for the staging of dementia. BrJ Psychiatry 1982;140: 1225-30.

Ihl R, Eilles C, Frlich L, Maurer K, Dierks T, Perisic I. Electrical brain activity and cerebral blood flow in dementia of the Alzheimer type. Psychiatry Res 1989;29(3):449-52.

Jelic V, Shigeta M, Julin P. Quantitative electroencephalography power and coherence in Alzheimer's disease and mild cognitive impairment. Dementia 1996;7:314-23.

Jelic V, Johansson SE, Almkvist O, Shigeta M, Julin P, Nordberg A, Winblad B, Wahlund LO. Quantitative electroencephalography in mild cognitive impairment: longitudinal changes and possible prediction of Alzheimer's disease. Neurobiol Aging 2000;21(4):533-40.

Jeong J. EEG dynamics in patients with Alzheimer's disease. Clin Neurophysiol 2004;115(7):1490-505.
Joannesson G, Brun A, Gustafson I, Ingvar DH. EEG in presenile dementia related to cerebral blood flow and autopsy findings. Acta Neurol Scand 1977;56:89-103.

Killiany RJ, Moss MB, Albert MS, Sandor T, Tieman J, Jolesz F. Temporal lobe regions on magnetic resonance imaging identify patients with early Alzheimer's disease. Arch Neurol 1993;50(9):949-54.

Klimesch W. Memory processes, brain oscillations and EEG synchronization. Int J Psychophysiol 1996;24(1-2):61-100.

Klimesch W. EEG alpha and theta oscillations reflect cognitive and memory performance: a review and analysis. Brain Res Brain Res Rev 1999;29:169-95.

Klimesch W, Doppelmayr M, Pachinger T, Russegger H. Event-related desynchronization in the alpha band and the processing of semantic information. Brain Res Cogn Brain Res 1997;6(2):83-94.

Klimesch W, Doppelmayr M, Russegger H, Pachinger T, Schwaiger J. Induced alpha band power changes in the human EEG and attention. Neurosci Lett 1998;244(2):73-6.

Koenig T, Prichep L, Dierks T, Hubl D, Wahlund LO, John ER, Jelic V. Decreased EEG synchronization in Alzheimer's disease and mild cognitive impairment. Neurobiol Aging 2005;26(2):165-71.

Kolev V, Yordanova J, Basar-Eroglu C, Basar E. Age effects on visual EEG responses reveal distinct frontal alpha networks. Clin Neurophysiol 2002;113(6):901-10.

Kwa VI, Weinstein HC, Posthumus-Meyjes EF, Van Royen EA, Bour LJ, Verhoeff PN, Ongerboer de Visser BW. Spectral analysis of the EEG and 99m-Tc-HMPAO-SPECT-scan in Alzheimer's disease. Biol Psychiatry 1993;33(2):100-7.

Larrieu S, Letenneur L, Orgogozo JM, Fabrigoule C, Amieva H, Le Carret N, Barberger-Gateau P, Dartigues JF. Incidence and outcome of mild cognitive impairment in a population-based prospective cohort. Neurology 2002;59:1594-9.

Laufer I, Pratt H. Evoked potentials to auditory movement sensation in duplex perception. Clin Neurophysiol 2003a;114(7):1316-31.

Laufer I, Pratt H. The electrophysiological net response ('F-complex') to spatial fusion of speech elements forming an auditory object. Clin Neurophysiol 2003b;114(5):818-34.

Lawton MP, Brodie EM. Assessment of older people: self maintaining and instrumental activity of daily living. J Gerontol 1969;9:179-86.

Leuchter AF, Cook IA, Newton TF, Dunkin J, Walter DO, RosenbergTompson S, Lachenbruch PA, Weiner H. Regional differences in brain electrical activity in dementia: use of spectral power and spectral ratio measures. Electroencephalogr Clin Neurophysiol 1993;87:385-93.

Manshanden I, De Munck JC, Simon NR, Lopes da Silva FH. Source localization of MEG sleep spindles and the relation to sources of alpha band rhythms. Clin Neurophysiol 2002;113(12):1937-47.

Mash DC, Flynn DD, Potter LT. Loss of M2 muscarine receptors in the cerebral cortex in Alzheimer's disease and experimental cholinergic denervation. Science 1985;228(4703):1115-7.

Massimini M, Huber R, Ferrarelli F, Hill S, Tononi G. The sleep slow oscillation as a traveling wave. J Neurosci 2004;24(31):6862-70.

McKeith IG, Perry EK, Perry RH. Report of the second dementia with Lewy body international workshop: diagnosis and treatment. Consortium on Dementia with Lewy Bodies. Neurology 1999;53:902-5.

McKhann G, Drachman D, Folstein M, Katzman R, Price D, Stadlan EM. Clinical diagnosis of Alzheimer's disease: report of the NINCDSADRDA Work Group under the auspices of Department of Health and Human Services Task Force on Alzheimer's disease. Neurology 1984; 34:939-44.

Meier-Ruge W, Ulrich J, Bruhlmann M, Meier E. Age-related white matter atrophy in the human brain. Ann NY Acad Sci 1992;673:260-9.

Mesulam M, Shaw P, Mash D, Weintraub S. Cholinergic nucleus basalis tauopathy emerges early in the aging-MCI-AD continuum. Ann Neurol 2004;55(6):815-28.

Moretti DV, Babiloni F, Carducci F, Cincotti F, Remondini E, Rossini PM, Salinari S, Babiloni C. Computerized processing of EEG-EOG-EMG artifacts for multicentirc studies in EEG oscillations and event-related potentials. Int J Pshycophysiol 2003;47(3):199-216. 
Moretti DV, Babiloni C, Binetti G, Cassetta E, Dal Forno G, Ferreri F, Ferri R, Lanuzza B, Miniussi C, Nobili F, Rodriguez G, Salinari S, Rossini PM. Individual analysis of EEG frequency and band power in mild Alzheimer's disease. Clin Neurophysiol 2004;115:299-308.

Mulert C, Gallinat J, Pascual-Marqui R, Dorn H, Frick K, Schlattmann P, Mientus S, Herrmann WM, Winterer G. Reduced event-related current density in the anterior cingulate cortex in schizophrenia. Neuroimage 2001;13(4):589-600.

Murri L, Gori S, Massetani R, Bonanni E, Marcella F, Milani S. Evaluation of acute ischemic stroke using quantitative EEG: a comparison with conventional EEG and CT scan. Neurophysiol Clin 1998;28(3):249-57.

Nobili F, Taddei G, Vitali P, Bazzano L, Catsafados E, Mariani G, Rodriguez G. Relationships between 99m Tc-HMPAO ceraspect and quantitative EEG observations in Alzheimer's disease. Arch Gerontol Geriatr 1998;6:363-8.

Nobili F, Vitali P, Canfora M, Girtler N, De Leo C, Mariani G, Pupi A, Rodriguez G. Effects of long-term Donepezil therapy on rCBF of Alzheimer's patients. Clin Neurophysiol 2002a;113(8):1241-8.

Nobili F, Koulibaly M, Vitali P, Migneco O, Mariani G, Ebmeier K, Pupi A, Robert PH, Rodriguez G, Darcourt J. Brain perfusion follow-up in Alzheimer's patients during treatment with acetylcholinesterase inhibitors. J Nucl Med 2002b;43(8):983-90.

Nunez PL, Wingeier BM, Silberstein RB. Spatial-temporal structures of human alpha rhythms: theory, microcurrent sources, multiscale measurements, and global binding of local networks. Hum Brain Mapp 2001;13(3):125-64.

Nuwer MR. Quantitative EEG I: techniques and problems of frequency analysis and topographic mapping. J Clin Neurophysiol 1988;5:1-43.

Ohnishi T, Matsuda H, Tabira T, Asada T, Uno M. Changes in brain morphology in Alzheimer disease and normal ageing: is Alzheimer disease an exaggerated aging process? AJNR Am J Neuroradiol 2001; 22:1680-5.

Pascual-Marqui RD, Michel CM. LORETA (low resolution brain electromagnetic tomography): new authentic 3D functional images of the brain. ISBET Newslett ISSN 1994;5:4-8.

Pascual-Marqui RD, Lehmann D, Koenig T, Kochi K, Merlo MC, Hell D, Koukkou M. Low resolution brain electromagnetic tomography (LORETA) functional imaging in acute, neuroleptic-naive, firstepisode, productive schizophrenia. Psychiatry Res 1999;90(3):169-79.

Pascual-Marqui RD, Esslen M, Kochi K, Lehmann D. Functional imaging with low resolution brain electromagnetic tomography (LORETA): a review. Methods Find Exp Clin Pharmacol 2002;24:91-5.

Passero S, Rocchi R, Vatti G, Burgalassi L, Battistini N. Quantitative EEG mapping, regional cerebral blood flow, and neuropsychological function in Alzheimer's disease. Dementia 1995;6:148-56.

Pennanen C, Testa C, Laakso MP, Hallikainen M, Helkala EL, Hanninen T, Kivipelto M, Kononen M, Nissinen A, Tervo S, Vanhanen M, Vanninen R, Frisoni GB, Soininen H. Voxel based morphometry study on mild cognitive impairment. J Neurol Neurosurg Psychiatry 2005;76(1):11-14.

Petersen RC, Smith GE, Ivnik RJ, Tangalos EG, Schaid SN, Thibodeau SN, Kokmen E, Waring SC, Kurland LT. Apolipoprotein E status as a predictor of the development of Alzheimer's disease in memoryimpaired individuals. J Am Med Assoc 1995;273:1274-8.

Petersen RC, Smith GE, Waring SC, Ivnik RJ, Kokmen E, Tangelos EG. Aging, memory, and mild cognitive impairment. Int Psychogeriatr 1997;9(Suppl. 1):65-9.

Petersen RC, Doody R, Kurz A, Mohs RC, Morris JC, Rabins PV, Ritchie K, Rossor M, Thal L, Winblad B. Current concepts in mild cognitive impairment. Arch Neurol 2001;58(12):1985-92.

Phillips C, Rugg MD, Friston KJ. Systematic regularization of linear inverse solutions of the EEG source localization problem. Neuroimage 2002;17:287-301.

Pierson R, Corson PW, Sears LL, Alicata D, Magnotta V, Oleary D, Andreasen NC. Manual and semiautomated measurement of cerebellar subregions on MR images. Neuroimage 2002;17(1):61-76.
Ponomareva NV, Selesneva ND, Jarikov GA. EEG alterations in subjects at high familial risk for Alzheimer's disease. Neuropsychobiology 2003; 48(3):152-9.

Prichep LS, John ER, Ferris SH, Reisberg B, Almas M, Alper K, Cancro R. Quantitative EEG correlates of cognitive deterioration in the elderly. Neurobiol Aging 1994;15(1):85-90 [Erratum in: Neurobiol Aging 1994 May-Jun;15(3):391].

Priori A, Foffani G, Pesenti A, Tamma F, Bianchi AM, Pellegrini M, Locatelli M, Moxon KA, Villani RM. Rhythm-specific pharmacological modulation of subthalamic activity in Parkinson's disease. Exp Neurol 2004;189(2):369-79.

Pucci E, Cacchiò G, Angeloni R, Belardinelli N, Nolfe G, Signorino M, Angeleri F. EEG spectral analysis in Alzheimer's disease and different degenerative dementias. Arch Gerontol Geriatr 1997;26:283-97.

Pucci E, Belardinelli N, Cacchio G, Signorino M, Angeleri F. EEG power spectrum differences in early and late onset forms of Alzheimer's disease. Clin Neurophysiol 1999;110(4):621-31.

Rae-Grant A, Blume W, Breslau C, Hachinski VC, Fisman M, Merskey H. The electroencephalogram in Alzheimer type dementia. A sequential study correlating the electroencephalogram with psycometric and quantitative pathological data. Arch Neurol 1987;44:50-5.

Ray PG, Jackson WJ. Lesions of nucleus basalis alter ChAT activity and EEG in rat frontal neocortex. Electroencephalogr Clin Neurophysiol 1991;79(1):62-8.

Ricceri L, Minghetti L, Moles A, Popoli P, Confaloni A, De Simone R, Piscopo P, Scattoni ML, di Luca M, Calamandrei G. Cognitive and neurological deficits induced by early and prolonged basal forebrain cholinergic hypofunction in rats. Exp Neurol 2004;189(1):162-72.

Rodriguez G, Nobili F, Rocca G, DeCarli F, Gianelli MV, Rosadini G. Quantitative electroencephalography and regional cerebral blood flow: discriminant analysis between Alzheimer's patients and healthy controls. Dement Geriatr Cogn Disord 1998;9:238-74.

Rodriguez G, Copello F, Nobili F, Vitali P, Perego G, Nobili F. EEG spectral profile to stage Alzheimer's disease. Clin Neurophysiol 1999a; 110:1831-7.

Rodriguez G, Nobili F, Copello F, Vitali P, Gianelli MV, Taddei G, Catsafados E, Mariani G. 99mTc-HMPAO regional cerebral blood flow and quantitative electroencephalography in Alzheimer's disease: a correlative study. J Nucl Med 1999b;40:522-9.

Rodriguez G, Vitali P, De Leo C, De Carli F, Girtler N, Nobili F. Quantitative EEG changes in Alzheimer patients during long-term donepezil therapy. Neuropsychobiology 2002;46:49-56.

Rogers J, Webster S, Lue LF, Brachova L, Civin WH, Emmerling M, Shivers B, Walker D, McGeer P. Inflammation and Alzheimer's disease pathogenesis. Neurobiol Aging 1996;17(5):681-6.

Roman GC, Tatemichi TK, Erkinjuntti T, Cummings JL, Masdeu JC, Garcia JH, Amaducci L, Orgogozo JM, Brun A, Hofman A. Vascular dementia: diagnostic criteria for research studies. Report of the NINDSAIREN international workshop. Neurology 1993;43(2):250-60.

Rombouts SA, Barkhof F, Witter MP, Scheltens P. Unbiased wholebrain analysis of grey matter loss in Alzheimer's disease. Neurosci Lett 2000; 285:231-3.

Rosen WG, Terry RD, Fuld PA, Katzman R, Peck A. Pathological verification of ischemic score in differentiation of dementias. Ann Neurol 1980;7(5):486-8.

Rossini PM, Desiato MT, Lavaroni F, Caramia MD. Brain excitability and electroencephalographic activation: non-invasive evaluation in healthy humans via transcranial magnetic stimulation. Brain Res 1991;567(1): $111-9$.

Rubin EH, Morris JC, Grant EA, Vendegna T. Very mild senile dementia of the Alzheimer type. I. Clinical assessment. Arch Neurol 1989;46(4): 379-82.

Saletu B, Anderer P, Saletu-Zyhlarz GM, Pascual-Marqui RD. EEG topography and tomography in diagnosis and treatment of mental disorders: evidence for a key-lock principle. Methods Find Exp Clin Pharmacol 2002;24(Suppl. D):97-106. 
Scheltens P, Fox N, Barkhof F, De Carli C. Structural magnetic resonance imaging in the practical assessment of dementia: beyond exclusion. Lancet Neurol 2002;1(1):13-21.

Sheridan PH, Sato S, Foster N, Bruno G, Cox C, Fedio P, Chase TN Relation of EEG alpha background to parietal lobe function in Alzheimer's disease as measured by positron emission tomography and psychometry. Neurology 1988;38:747-50.

Sloan EP, Fenton GW, Kennedy NSJ, MacLennan JM. Electroencephalography and single photon emission computed tomography in dementia: a comparative study. Psychol Med 1995;25:631-8.

Small GW, La Rue A, Komo S, Kaplan A, Mandelkern MA. Predictors of cognitive change in middle-aged and older adults with memory loss. Am J Psychiatry 1995;152(12):1757-64.

Steriade M. Sleep oscillations and their blockage by activating systems. J Psychiatry Neurosci 1994;19(5):354-8.

Steriade M. Neuronal substrates of sleep and epilepsy. Cambridge, UK: Cambridge University Press; 2003. p. 522.

Steriade M, Llinas RR. The functional states of the thalamus and the associated neuronal interplay. Physiol Rev 1988;68(3):649-742.

Steriade M, Amzica F, Contreras D. Synchronization of fast $(30-40 \mathrm{~Hz})$ spontaneous cortical rhythms during brain activation. J Neurosci 1996; 16:392-417.

Stewart GR, Frederickson CJ, Howell GA, Gage FH. Cholinergic denervation-induced increase of chelatable zinc in mossy-fiber region of the hippocampal formation. Brain Res 1984;290(1):43-51.

Stigsby B, Johannesson G, Ingvar DH. Regional EEG analysis and regional cerebral blood flow in Alzheimer's and Pick's diseases. Electroencephalogr Clin Neurophysiol 1981;51:537-47.

Szava S, Valdes P, Biscay R, Galan L, Bosch J, Clark I, Jimenez JC. High resolution quantitative EEG analysis. Brain Topogr 1994;6(3):211-9.

Szelies B, Grond M, Herholz K, Kessler J, Wullen T, Heiss WD. Quantitative EEG mapping and PET in Alzheimer's disease. J Neurol Sci 1992;110:46-56.

Szelies B, Mielke R, Kessler J, Heiss WD. EEG power changes are related to regional cerebral glucose metabolism in vascular dementia. Clin Neurophysiol 1999;110(4):615-20.

Talairach J, Tournoux P. Co-planar stereotaxic atlas of the human brain. Stuttgart: Thieme; 1988.

Tanaka Y, Hanyu H, Sakurai H, Takasaki M, Abe K. Atrophy of the substantia innominata on magnetic resonance imaging predicts response to donepezil treatment in Alzheimer's disease patients. Dement Geriatr Cogn Disord 2003;16:119-25.

Testa C, Laakso MP, Sabattoli F, Rossi R, Beltramello A, Soininen H, Frisoni GB. A comparison between the accuracy of voxel-based morphometry and hippocampal volumetry in Alzheimer's disease. J Magn Reson Imaging 2004;19(3):274-82.

The Lund and Manchester Groups. Clinical and neuropathological criteria for frontotemporal dementia. J Neurol Neurosurg Psychiatry 1994 Apr;57(4):416-8.

Tullberg M, Fletcher E, DeCarli C, Mungas D, Reed BR, Harvey DJ, Weiner MW, Chui HC, Jagust WJ. White matter lesions impair frontal lobe function regardless of their location. Neurology 2004;63(2): 246-53.

Valdes P, Picton TW, Trujillo N, Bosch J, Aubert E, Riera J. Constraining EEG-MEG source imaging with statistical neuroanatomy. Neuroimage 1998;4:635.

Veiga H, Deslandes A, Cagy M, Fiszman A, Piedade RA, Ribeiro P. Neurocortical electrical activity tomography in chronic schizophrenics. Arq Neuropsiquiatr 2003;61(3B):712-7 [Epub 2003 Oct 28].

Winterer G, Mulert C, Mientus S, Gallinat J, Schlattmann P, Dorn H, Herrmann WM. P300 and LORETA: comparison of normal subjects and schizophrenic patients. Brain Topogr 2001;13(4):299-313.

Wolf H, Jelic V, Gertz H-J, Nordberg A, Julin P, Wahlund LO. A critical discussion of the role of neuroimaging in mild cognitive impairment. Acta Neurol Scand 2003;107(Suppl. 179):52-76.

Yao D, He B. A self-coherence enhancement algorithm and its application to enhancing three-dimensional source estimation from EEGs. Ann Biomed Eng 2001;29:1019-27.

Yesavage JA, Brink TL, Rose TL, Lum O, Huang V, Adey M, Leirer VO. Development and validation of a geriatric depression screening scale: a preliminary report. J Psychiatr Res 1982-83;17(1):37-49.

Zappoli R, Versari A, Paganini M, Arnetoli G, Muscas GC, Gangemi PF, Arneodo MG, Poggiolini D, Zappoli F, Battaglia A. Brain electrical activity (quantitative EEG and bit-mapping neurocognitive $\mathrm{CNV}$ components), psychometrics and clinical findings in presenile subjects with initial mild cognitive decline or probable Alzheimer-type dementia. Ital J Neurol Sci 1995;16(6):341-76.

Zaudig M. A new systematic method of measurement and diagnosis of 'mild cognitive impairment' and dementia according to ICD-10 and DSM-III-R criteria. Int Psychogeriatr 1992;4(Suppl. 2):203-19. 